\title{
Climate-related changes in marine ecosystems simulated with a 3-dimensional coupled physical-biogeochemical model of the Baltic Sea
}

\author{
H. E. Markus Meier ${ }^{1,2, *}$, Kari Eilola ${ }^{1}$, Elin Almroth ${ }^{1}$ \\ ${ }^{1}$ Swedish Meteorological and Hydrological Institute, Folksborgsvägen 1, 60176 Norrköping, Sweden \\ ${ }^{2}$ Department of Meteorology, Arrhenius Laboratory, Svante Arrhenius väg 16C, Stockholm University, 10691 Stockholm, Sweden
}

\begin{abstract}
The combined effect of changing climate and changing nutrient loads from land due to altered land use, sewage water treatment and emissions was studied using a 3-dimensional highresolution coupled physical-biogeochemical model for the Baltic Sea. Results suggest that global warming causes increased water temperatures and reduced sea ice cover, combined (eventually) with increased winter mean wind speeds and increased river runoff. The projected hydrographic changes could therefore have significant effects on the marine ecosystem. These changes may compete with nutrient load reductions - presently under discussion - that aim to improve the ecological status of the Baltic Sea. Targets that may be sufficient in the present climate might fail under future climate conditions. Using the model, we investigated 4 climate change scenarios and 3 nutrient load scenarios, ranging from a pessimistic 'business as usual' to the 'most optimistic' case (including the Baltic Sea Action Plan, BSAP). In addition, using cause-and-effect studies, we analyzed changing simulated nutrient cycles, oxygen concentrations, and phytoplankton concentrations. As model results for the northern part of the Baltic (Bothnian Bay and Bothnian Sea) are not reliable, we focus the analysis on the Baltic proper, including the Arkona, Bornholm and Gotland basins. The degree of nutrient reduction in nutrient-load reduction scenarios is likely to differ under a future climate, but actions of the BSAP will reduce phytoplankton concentrations also in the future climate. However, the sensitivity of non-linear responses to climate change depends on processes that are not well understood, with current understanding limited by modelling uncertainties (e.g. in the long-term functioning of Baltic Sea sediments as sources and sinks of nutrients).
\end{abstract}

KEY WORDS: Numerical modeling · Climate change $\cdot$ Eutrophication · Marine ecosystems · Scenarios · Baltic Sea Action Plan

\section{INTRODUCTION}

The Baltic Sea is a semi-enclosed sea having limited water exchange with the world ocean (Fig. 1). About 85 million people live in the Baltic drainage basin, which is more than 4 times larger than the Baltic Sea surface area. During pre-industrial conditions ( $>100$ years ago) the Baltic was an oligotrophic system (e.g. Schernewski \& Neumann 2005, Savchuk et al. 2008). Population increase and agricultural intensification led to increased nutrient loads entering the sea.
Today eutrophication is thought to be the most severe threat to the Baltic Sea ecosystem (e.g. Boesch et al. 2006, 2008, Pawlak et al. 2009). During recent decades, eutrophication-associated problems-such as deep water oxygen deficiency, the spreading of dead bottom zones, increased frequency and intensity of cyanobacterial blooms - have been observed (e.g. Wulff et al. 2001, Vahtera et al. 2007, Diaz \& Rosenberg 2008, Conley et al. 2009a).

Consequently, measures against eutrophication in the Baltic Sea have been intensively discussed- 


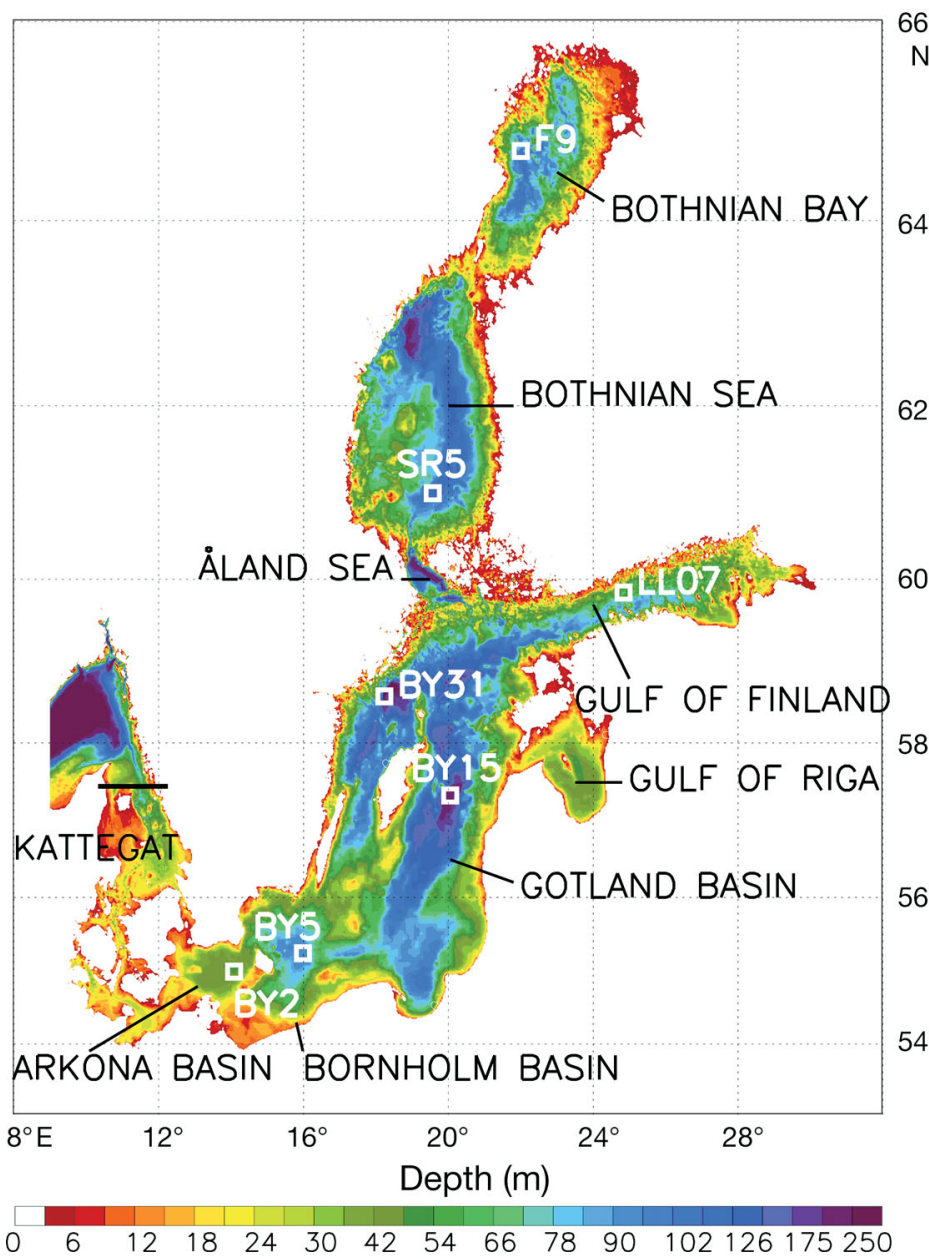

Fig. 1. Bottom topography of the Baltic Sea. The domain of the Swedish Coastal and Ocean Biogeochemical model coupled to the Rossby Centre Ocean model (RCO-SCOBI) is limited with open boundaries in the northern Kattegat (black line). Monitoring stations-BY2: Arkona Deep; BY5: Bornholm Deep; BY15: Gotland Deep; BY31: Landsort Deep; LL07: Gulf of Finland; SR5: Bothnian Sea; F9: Bothnian Bay

prominent examples are: nutrient load reductions (e.g. by the Helsinki Commission, HELCOM, see www. helcom.fi; Savchuk \& Wulff 2007, 2009, Savchuk et al. 2009); engineering methods including the oxygenation of the halocline between 60 and $120 \mathrm{~m}$ (Stigebrandt \& Gustafsson 2007) and precipitation of phosphorus (Blomqvist \& Rydin 2009); and biomanipulation of the food web utilizing a top-down approach. Gustafsson et al. (2008) and Conley et al. (2009b) have concluded that in the long term, the only measure that is likely to help regenerate the Baltic Sea ecosystem is a reduction in nutrient loads.

In November 2007 the ministers of all Baltic Sea countries signed the ambitious Baltic Sea Action Plan (BSAP, www.helcom.fi), with the aim of reducing nutrient loads. However, the response of the Baltic Sea is slow, and an improvement is expected only several $6^{\circ}$ decades after implementation of the measures. $\mathrm{N}$ As the response time of the total phosphorus pool may be $>50$ years (Savchuk \& Wulff 2007, 2009), changes in climate also have to be taken into account, since the calculated reductions in nutri$64^{\circ}$ ent load may not have the same biophysical effect in a future climate as they would in the present climate.

Changes in climate have marked effects on the marine environment because (1) variations in physical conditions affect biogeochemical cycles (e.g. Janssen et al. 2004, Neumann \& Scher newski 2008, Conley et al. 2009a, Eilola et al. 2009), and (2) sediment cores from the Baltic proper (including the Arkona, Bornholm and Gotland basins) suggest that during the Holocene Thermal Maximum (ca. 9000 to 5000 yr BP), that was characterised by warmer and saltier water conditions, sediments were laminated, indicating recurring periods of hypoxia similar to present environmental conditions (Zillén et al. 2008).

Thus, in addition to changing nutrient loads from land and atmosphere, a changing climate has to be considered. In the recent Baltic Sea $54^{\circ}$ Experiment (BALTEX) Assessment of Climate Change for the Baltic Sea Basin (BACC, www. baltex-research.eu/BACC) it was concluded that global warming may cause hydrographic changes that have significant impacts on marine ecosystems and biodiversity (BACC author team 2008).

Earlier results from regional climate modelling suggest that, for instance, the annual mean sea surface temperature (SST) averaged for the Baltic Sea area may increase between 2 and $4^{\circ} \mathrm{C}$, depending on the greenhouse gas emission scenario and on the global climate model (GCM) used (Döscher \& Meier 2004, Meier 2006). In simulations by Meier et al. (2004a), the largest SST increase was found during summer (June to August) in the Bothnian Sea and Bothnian Bay due to melting sea ice in the northern sub-basins and a subsequently longer warm-up period during spring. The mean maximum ice extent might be reduced by 60 to $70 \%$, with mean conditions becoming ice free in the Bothnian Sea and large parts of the Gulf of Finland and Gulf of Riga (Meier et al. 2004a).

The global mean sea level is projected to rise between 0.18 and $0.59 \mathrm{~cm}$ (Solomon et al. 2007). In the northern Baltic this increase may partly be compensated due to land uplift (Meier et al. 2004b). Annual mean sea level and sea level extremes, especially in the southeastern Baltic, may increase compared to the present climate (Meier et al. 2004b, Meier 2006). A sea level rise/decrease of up to $\sim 50 \mathrm{~cm}$ will not have a 
major effect on the exchange of water between the Baltic Sea and the North Sea (Gustafsson 2004), but sea level increase may be larger than projected (e.g. Rahmstorf 2007, Pfeffer et al. 2008).

As salinity changes in the Baltic Sea are caused by both wind and river flow changes, projections of salinity are rather uncertain (Meier 2006, Meier et al. 2006). According to available simulations using different scenarios, projected salinity ranges from no change to a significant reduction of up to $50 \%$ (Meier et al. 2006). However, the effects of sea level changes larger than those previously proposed by Solomon et al. (2007) have not been taken into account in these estimations.

In this study we investigated the combined effects of changing climate and nutrient load scenarios using a 3-dimensional coupled physical-biogeochemical model of the Baltic Sea (Eilola et al. 2009). We utilised 4 future climate projections and 3 nutrient load scenarios, with the aim of representing a broad range of uncertainties regarding accelerated emissions of greenhouse gases and air- and riverborne nutrient loads to the sea. Assessment of future eutrophication needs to take into account land-based processes, as well as socioeconomic and socio-political aspects (e.g. future lifestyle, affecting inter alia meat consumption and agricultural practices).

In addition, we aim to delineate the marine ecosystem response to various drivers in the simulations (under different scenarios), using cause-and-effect studies - for instance, the effect on the marine ecosystem of higher water temperature, increased surface wind speeds and altered nutrient loads.

The paper is organized as follows. In Section 2, the methods and models are explained. Although a thorough validation of the model results is beyond the scope of this study, in the first part of Section 3 a few examples of model performance-comparing model results and observations-are discussed. The main part of Section 3 focuses on the presentation of results of simulations under different scenarios, and of causeand-effect studies. This is followed with the Discussion and Conclusions in Sections 4 and 5, respectively.

\section{METHODS}

\subsection{Dynamical downscaling and delta approach}

Driven by data from GCMs at the lateral boundaries, the Rossby Centre Atmosphere Ocean model, RCAO (Döscher et al. 2002), was used to regionalize climate change at the end of the late 21st century in the Baltic Sea catchment area (Räisänen et al. 2004). The 2 GCMs used were HadAM3H from the Hadley Centre in the UK (Pope et al. 2000, Gordon et al. 2000) and
ECHAM4/OPYC3 from the Max Planck Institute for Meteorology in Germany (Roeckner et al. 1999). For each of the 2 GCMs, 2 scenarios with different greenhouse gas emissions (A2, B2; see Nakićenović et al. 2000) were conducted. In total, a series of six $30 \mathrm{yr}$ time slice experiments was performed: 2 control simulations representing the recent climate (1961-1990) and 4 simulations with A2 or B2 emission scenario, representing the climate of the late 21st century (2071-2100). For further details see Räisänen et al. (2004) for the model setup and Döscher \& Meier (2004) and Meier et al. (2004a) for the oceanic results of the RCAO simulations.

Since 30 yr long simulations are too short to spin up salinity and other deep water variables that have longer response time scales, the so-called delta approach has been applied, assuming that the temporal variability of the forcing does not change with a future climate. Only the climatologically mean seasonal cycles may vary. The atmospheric forcing fields of the ocean model representing 2071-2100 were calculated by adding the climatological monthly mean changes of $2 \mathrm{~m}$ air temperature, $2 \mathrm{~m}$ specific humidity, total cloudiness, sea level pressure (SLP), and precipitation from the RCAO simulations to reconstructed atmospheric surface fields for the reference period 19031998 (Kauker \& Meier 2003, Meier \& Kauker 2003). The temporal resolution of these reconstructed atmospheric surface fields is monthly except for the $10 \mathrm{~m}$ wind fields, which were derived from daily SLP using a simple boundary layer parameterization over the sea, taking the distance to the coast into account. For the future climate, $10 \mathrm{~m}$ wind fields were calculated from the sum of daily reconstructed SLP fields and climatological monthly mean SLP changes from the simulations. Standard bulk formulae were used to calculate sea surface fluxes of momentum, sensible and latent heat, incoming short- and long-wave radiation, and evaporation. The daily cycle of the incoming short-wave radiation was resolved. A similar approach was used utilizing a large-scale hydrological model to calculate future river discharge from precipitation and air temperature modeled with RCAO (Graham 2004, Graham et al. 2007). The atmospheric and hydrological fields were used to force the ocean component of RCAO (RCO) to perform simulations under different scenarios for 2071-2100 based upon the temporal variability of 1969-1998. For details of the model approach see Meier (2006).

Physical characteristics of the 4 climate projections were as follows. In the simulations forced by HadAM3H, mainly water temperature increases, whereas salinity and mixing do not change significantly. In the corresponding emission scenarios B2 and A2, SSTs averaged for the entire Baltic Sea including Kattegat increase by $+2.1^{\circ} \mathrm{C}$ and $+3.2^{\circ} \mathrm{C}$, respectively. In addi- 
tion to increases in water temperature, in the ECHAM4/ OPYC3-driven simulations, salinity and mixing also change. In the $\mathrm{B} 2$ and $\mathrm{A} 2$ emission scenarios SSTs increase by $+2.9^{\circ} \mathrm{C}$ and $+3.7^{\circ} \mathrm{C}$, respectively. Due to increased west wind and increased river flow, sea surface salinities (SSSs) decrease by -3.0 and $-3.2 \mathrm{psu}$, respectively (Table 1). Due to increased mixing the halocline in the Baltic proper is located deeper. For a detailed description of changing hydrography in the simulations, see Meier (2006). Note that so far the RCAO simulations used by Räisänen et al. (2004) are the only available consistent and fully coupled atmosphere-ice-ocean simulations for the Baltic Sea catchment area.

\subsection{Coupled physical-biogeochemical model}

The method by Meier (2006) was applied to assess the response of biogeochemical cycles to changing forcing conditions. For this purpose we use a state-ofthe-art coupled physical-biogeochemical model, the Swedish Coastal and Ocean Biogeochemical model (SCOBI) coupled to the Rossby Centre Ocean model (RCO), i.e. RCO-SCOBI (Eilola et al. 2009). The model domain covers the Baltic Sea including the Kattegat (Fig.1) with a $6 \mathrm{n}$ mile horizontal grid resolution and 41 vertical levels with an increasing layer thickness from the surface to the bottom from 3 to $12 \mathrm{~m}$. The time step of both the physical and the biogeochemical submodels amounts to $600 \mathrm{~s}$.

The biogeochemical sub-model describes the dynamics of nitrate, ammonium, phosphate, phytoplankton, zooplankton, detritus, and oxygen (Fig. 2). Here, phytoplankton consists of 3 algal groups representing diatoms, flagellates and others, and cyanobacteria. Besides the possibility of assimilating inorganic nutrients, the modelled cyanobacteria also have the ability to fix molecular nitrogen, which may constitute an external nitrogen source for the model system. The sediment contains nutrients in the form of benthic nitrogen and benthic phosphorus, including aggregated process descriptions for oxygen-dependent nutrient regeneration, denitrification and adsorption of ammonium to sediment particles, as well as permanent burial of organic matter. During periods with strong currents, resuspension occurs and sediments may be lifted up into the overlying water and become transported to deeper parts. Anoxic decomposition processes utilize oxygen from nitrate reduction (denitrification) and thereafter from sulphate reduction. Sulphate reduction produces poisonous hydrogen sulphide that is included as negative oxygen in the model. Hydrogen sulphide may be removed when new oxygen is supplied, e.g. by inflowing water.
As the Baltic is a shallow sea with a mean depth of $53 \mathrm{~m}$, nutrient fluxes between bottom water and sediments are important. However, the processes in the sediments are not well understood, and might be regarded as one of the bottlenecks in state-of-the-art biogeochemical modeling (Eilola et al. 2009, 2010). The model calibration has shown that the permanent sink of phosphorus (burial rate in the sediments) has a major effect on Baltic Sea nutrient cycling at longer time scales, i.e. decades. The regulation of phosphorus

Table 1. Simulations performed. The notation of a specific simulation contains the information of the climate scenario, nutrient loads and version number, e.g. EA2-BSAP-2 for ECHAM4/A2 combined with the BSAP nutrient loads using the modified sediment module (version 2). See Section 2.1 for details

\begin{tabular}{|c|c|c|}
\hline Acronym & Scenario & Characteristics \\
\hline C & Control & Present climate \\
\hline HB2 & HadAM3H/B2 & $\Delta \mathrm{SST}=+2.1^{\circ} \mathrm{C}$ \\
\hline HA2 & HadAM3H/A2 & $\Delta \mathrm{SST}=+3.2^{\circ} \mathrm{C}$ \\
\hline EB2 & ECHAM4/B2 & $\begin{array}{l}\Delta \mathrm{SST}=+2.9^{\circ} \mathrm{C} \\
\Delta \mathrm{SSS}=-3.0 \mathrm{psu} \\
\text { increased mixing }\end{array}$ \\
\hline EA2 & ECHAM4/A2 & $\begin{array}{l}\Delta \mathrm{SST}=+3.7^{\circ} \mathrm{C} \\
\Delta \mathrm{SSS}=-3.2 \mathrm{psu} \\
\text { increased mixing }\end{array}$ \\
\hline EA2-temp & ECHAM4/A2 & $\begin{array}{l}\text { Changes only in air } \\
\text { temperature and } \\
\text { specific humidity, } \\
\Delta \mathrm{SST}=+3.7^{\circ} \mathrm{C}\end{array}$ \\
\hline EA2-wind & ECHAM4/A2 & $\begin{array}{l}\text { Changes only in } \\
\text { wind forcing }\end{array}$ \\
\hline $\begin{array}{l}\text { EA2-wind + } \\
\text { runoff }\end{array}$ & ECHAM4/A2 & $\begin{array}{l}\text { Changes as in EA2 } \\
\text { except for air } \\
\text { temperature and } \\
\text { specific humidity }\end{array}$ \\
\hline REF & $\begin{array}{l}\text { Contemporary } \\
\text { nutrient loads }\end{array}$ & $\begin{array}{l}\text { Nutrient loads } \\
\text { during 1969-1998: } \\
\mathrm{P}=35 \mathrm{kt} \mathrm{yr}^{-1} \\
\mathrm{~N}=858 \mathrm{kt} \mathrm{yr}^{-1}\end{array}$ \\
\hline $\mathrm{BC}$ & Best case & $\begin{array}{l}\Delta \mathrm{P}=-18 \mathrm{kt} \mathrm{yr}^{-1} \\
(-51 \%) \\
\Delta \mathrm{N}=-155 \mathrm{kt} \mathrm{yr}^{-1} \\
(-18 \%)\end{array}$ \\
\hline BSAP & $\begin{array}{l}\text { Baltic Sea } \\
\text { Action Plan }\end{array}$ & $\begin{array}{l}\Delta \mathrm{P}=-14 \mathrm{kt} \mathrm{yr}^{-1} \\
(-39 \%) \\
\Delta \mathrm{N}=-132 \mathrm{kt} \mathrm{yr}^{-1} \\
(-15 \%)\end{array}$ \\
\hline BAU & $\begin{array}{l}\text { 'Business as usual' } \\
\text { in agriculture }\end{array}$ & $\begin{array}{l}\Delta \mathrm{P}=+14 \mathrm{kt} \mathrm{yr}^{-1} \\
(+39 \%) \\
\Delta \mathrm{N}=+290 \mathrm{kt} \mathrm{yr}^{-1} \\
(+34 \%)\end{array}$ \\
\hline 1 & $\begin{array}{l}\text { Reference version } \\
\text { of SCOBI }\end{array}$ & $\begin{array}{l}\text { Marmefelt et al. } \\
\text { (1999), Savchuk \& } \\
\text { Wulff (1996) }\end{array}$ \\
\hline 2 & $\begin{array}{l}\text { Modified sediment } \\
\text { module }\end{array}$ & Eilola et al. (2009) \\
\hline
\end{tabular}


Fig. 2. Schematic of the SCOBI model. Sediment variables and processes are shown in the lower left box. ZOO: zooplankton; DET: detritus; NBT and PBT: benthic nitrogen and phosphorus, respectively. Note that the process descriptions for oxygen and hydrogen sulphide are much simplified for clarity. For details see Eilola et al. (2009)

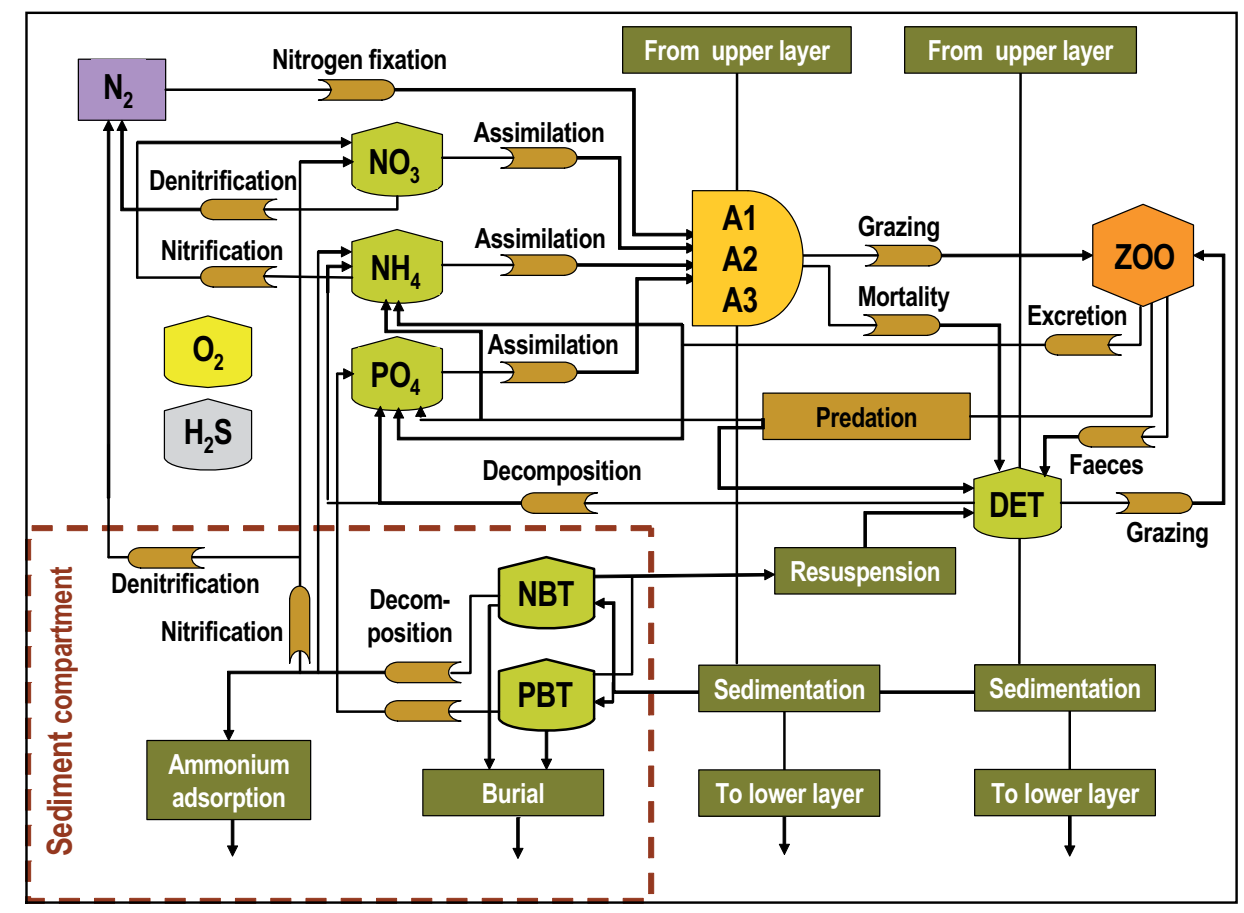

fluxes by oxygen concentrations is important for phosphorus cycling at seasonal and interannual time scales (Conley et al 2002). However, nitrogen dynamics is selfadjusting through the internal sources (nitrogen fixation) and sinks (denitrification). Consequently, fluxes of the nitrogen cycles have not been calibrated.

To estimate the uncertainty of the system response due to unknown sediment processes, all simulations have been performed with 2 versions of the sediment module. The reference version (no. 1) utilizes an oxygen-dependent sediment phosphorus release capacity (PRC) following Savchuk \& Wulff (1996). In the modified version (no. 2) the PRC is also salinity-dependent, taking regional varying fluxes into account.

The implementation of a salinity-dependent PRC in the model is motivated by the suggestion that the redox-dependent release and adsorption mechanisms of iron-bound phosphorus mainly control the outflow of phosphorus from the sediment to the overlying water (e.g. Sundby et al. 1992). In the mineralization process of organic material, oxygen is used as a primary electron acceptor, while other electron acceptors are used during anoxic conditions (Canfield et al. 2005). In an oxic environment, iron is present as Fe(III) oxide on which phosphate can adsorb and settle in the sediment. As the more favourable electron acceptors such as oxygen, nitrate and manganese oxide are depleted in the remineralisation process, the Fe(III) oxides are used and reduced to dissolved Fe(II). In this process the adsorbed phosphorus is released, and may become bio-available again. It has been suggested that differences in the availability of iron in systems that are more freshwater dominated (relative to marine systems) may regulate the precipitation capacity for phosphorus (e.g. Blomqvist et al. 2004). These differences are suggested to be related to the supply of sulfide from anaerobic bacterial reduction of sulfate in sea salt, which precipitates iron as sulfides and thus decreases the availability of iron on which phosphate can adsorb and settle in the sediment. Runoff from land brings both iron and humic substances, which may also increase the phosphorus-binding capacity in the sediments of the more freshwater influenced areas (Skoog et al. 1996).

In order to model the different PRCs under oxic and anoxic conditions and in areas with different salinity levels, a salinity- and oxygen-dependent parameterization of the benthic phosphorus fluxes in the model is used. There is a rapid change of the PRC of modeled sediments when the water becomes anoxic, and a sudden increase of PRC when the salinity increases from about 4.5 to 5.5 psu. The calibration of PRC indicated that at high oxygen concentrations, $\sim 30 \%$ of the mineralized phosphorus in the sediments is released as a flux of phosphate to the overlying water in saline areas ( $>5.5 \mathrm{psu}$ ) while only about $15 \%$ is released in the low saline Bothnian Bay $(<4.5 \mathrm{psu})$. The released fraction increases rapidly when the oxygen concentrations decrease below about $3 \mathrm{ml} \mathrm{l}^{-1}$ and exceeds $100 \%$ when the water turns anoxic (in this case, some of the previously adsorbed phosphorus may also be released and added to the flux of mineralized phosphorus into the 
overlying water). The salinity-dependent PRC has been used with good results both in the horizontally integrated BALTSEM model of the Baltic Nest Institute (Oleg Savchuk, pers.comm.) and in RCO-SCOBI (Eilola et al. 2009).

\subsection{Biogeochemical model strategy}

RCO-SCOBI simulations were performed with reconstructed atmospheric forcing and river discharge data for 1903-1998 (Kauker \& Meier 2003, Meier \& Kauker 2003). Thus the simulated daily to monthly variability of physical parameters follows the variability of instrumental records during the past $100 \mathrm{yr}$. As reconstructions of the last century of nutrient flows from land to the sea (including rivers, point sources and coastal runoff) and of atmospheric deposition are not available, biogeochemical parameters are forced with climatological data. From 1970 to the mid 1990s the total riverine loads of nitrogen and phosphorus to the Baltic Sea were fairly constant, with large interannual variability correlated to the river runoff (Stålnacke et al 1999). Hence, the nutrient flows of 29 rivers in the RCO, incorporating all runoff variability, are calculated as the product of climatological monthly mean concentrations of 1970-2000 and monthly volume flows of 1903-1998. Variations on the daily scale have been neglected because daily nitrogen and phosphorus load anomalies have been estimated to be $<\sim 1 \%$ of the annual average pools of dissolved inorganic nitrogen (DIN) and phosphorus (DIP), and even lower compared to the total pools. Point sources and atmospheric nitrogen deposition are based on an average of HELCOM estimates from the 1980s and 1990s. Atmospheric and river data were extracted from the Baltic Environmental Database (BED) via the internet based software NEST (www. balticnest.org). The temporal variability of the biogeochemical cycles during the last 3 decades of the simulation period (1969-1998) is quite realistic compared to observations (Eilola et al. 2009). However, by definition multi-decadal trends between pre-industrial and present environmental states (including the eutrophication caused by increased usage of fertilizer in agriculture since the 1950s) cannot be reproduced. Thus, for the analysis, only the last $30 \mathrm{yr}$ of the simulation period (1969-1998) were used. The approach is relatively simple and does not include the effect of changing precipitation patterns on nutrient flows, such as increased rates of farm field flushing due to intense rainfall. Possible future changes in load are assumed to be covered by the applied socio-economic scenarios. For details of the model strategy see Eilola et al. (2009).

\subsection{Ensemble approach}

In order to find out which of the results are 'robust', the uncertainties of the simulations were estimated using an ensemble approach, consisting of 40 ensemble members. Uncertainties arise from natural variability when the time slices are too short, from model biases of the GCMs and of the regional climate model $\mathrm{RCAO}$, from the lack of knowledge about biogeochemical processes, and from unknown socio-economic scenarios-including, e.g. greenhouse gas emission scenarios, land use scenarios, and sewage water treatment scenarios. Per definition 'robust' results are found commonly in all simulations of our ensemble.

In this study 4 climate scenarios (driven by 2 GCMs and 2 greenhouse gas emission scenarios, see Section 2.1), 3 nutrient load scenarios and 2 differing versions of the biogeochemical model SCOBI (Section 2.2) have been investigated, resulting in a matrix of $5 \times 4 \times 2=40$ simulations including contemporary climate and contemporary nutrient loads from land (Section 2.3), see Table 1. During 1968-1997 the biologically available total phosphorus and nitrogen loads from rivers, point sources and atmospheric deposition in RCO-SCOBI amount to 35 and $858 \mathrm{kt} \mathrm{yr}^{-1}$ for phosphorus and nitrogen loads, respectively (cf. Eilola et al. 2009). In Table 2 the corresponding figures for the sub-basins are listed.

The 3 nutrient load scenarios are based upon projections calculated by the Baltic Nest Institute at Stockholm University and adopted by HELCOM (Baltic Nest Institute 2007). In the best case scenario (BC), improved sewage water treatment, the use of only phos-

Table 2. Average (1968-1997) biologically available total phosphorus and nitrogen supply $\left(10^{3} \mathrm{t} \mathrm{yr}^{-1}\right)$ to the Baltic sub-basins

\begin{tabular}{|c|c|c|c|c|}
\hline & Rivers & $\begin{array}{c}\text { Point } \\
\text { sources }\end{array}$ & $\begin{array}{l}\text { Atmo- } \\
\text { sphere }\end{array}$ & Total \\
\hline \multicolumn{5}{|l|}{ Phosphorus } \\
\hline Bothnian Bay & 1.97 & 0.14 & 0.23 & 2.35 \\
\hline Bothnian Sea & 1.67 & 0.39 & 0.46 & 2.53 \\
\hline Gulf of Finland & 4.30 & 2.58 & 0.19 & 7.08 \\
\hline Gulf of Riga & 1.61 & 0.36 & 0.12 & 2.09 \\
\hline Baltic proper & 15.22 & 1.75 & 1.33 & 18.31 \\
\hline Kattegat $^{\mathrm{a}}$ & 1.21 & 1.27 & 0.31 & 2.79 \\
\hline Total & 25.99 & 6.50 & 2.65 & 35.14 \\
\hline \multicolumn{5}{|l|}{ Nitrogen } \\
\hline Bothnian Bay & 19.35 & 2.08 & 10.45 & 31.88 \\
\hline Bothnian Sea & 23.34 & 4.33 & 31.83 & 59.49 \\
\hline Gulf of Finland & 75.38 & 20.40 & 18.56 & 114.35 \\
\hline Gulf of Riga & 50.80 & 2.46 & 16.22 & 69.48 \\
\hline Baltic proper & 288.51 & 15.69 & 176.69 & 480.89 \\
\hline Kattegat $^{\mathrm{a}}$ & 38.04 & 8.86 & 55.14 & 102.04 \\
\hline Total & 495.41 & 53.82 & 308.89 & 858.13 \\
\hline
\end{tabular}


phorus free detergents and best possible agricultural practices have been combined. Following the BSAP, similar drastic reductions are anticipated. In the third scenario, 'business as usual' in agriculture is assumed (BAU). This means that all Baltic Sea countries would follow the past development of Denmark in agriculture causing a large increase of the total flows of phosphorus and nitrogen. Of all Baltic Sea countries, the exponential growth of agriculture in Denmark was the highest.

The atmospheric deposition and the lateral boundary conditions in the Kattegat were assumed to be unchanged in all scenarios. The values for rivers and point sources used in this study differ slightly from the loads published by the Baltic Nest Institute (2007) because the reference periods differ. Annual average loads used in this study and those reported to HELCOM refer to 1968-1997 and 1997-2003, respectively. In the simulations, the relative nutrient load changes per sub-basin given by the Baltic Nest Institute (2007) were used as factors for our reference concentrations, as given by Table 2 . Thus in the simulations, the nutrient flows from rivers were modified, both due to changing volume flows (a consequence of changing precipitation and evapotranspiration over land) and changing nutrient concentrations (a consequence of changing land-use, sewage water treatment, usage of phosphorus-free detergents, etc.). Note that point sources discharge into in the same grid boxes as the rivers (Eilola et al. 2009). But the point sources were not connected to the river runoff, since they discharge directly to the sea; hence they do not change when runoff is changing.

Figs. $3 \& 4$ show changes of annual mean volume flow of water and nutrient loads into the Bothnian Bay, Bothnian Sea, Gulf of Finland, Gulf of Riga, Baltic proper, Kattegat (without River Göta Älv) and the total Baltic basin (including the Kattegat), relative to the control simulation (C-REF) in all 19 simulations with differing climates and loads.

\subsection{Cause-and-effect studies}

In addition to the ensemble of simulations, a number of cause-and-effect studies have been performed to investigate the role of various forcing functions for the simulated response in the scenarios. In particular, we have investigated the climate scenario EA2 (with forcing from ECHAM4/A2) because the results from this experiment are more difficult to understand than from HA2 (with forcing from HadAM3H/A2). At least 3 drivers (air temperature, wind speed and nutrient loads) interact with each other. In the experiments EA2-temp, EA2-wind, and EA2-wind+runoff, the same atmospheric and hydrological forcing as in EA2 have been applied, but only changing air temperature and specific humidity (EA2-temp), changing wind forcing (EA2-wind) or changing wind, cloudiness, rain and runoff (EA2wind+runoff) have been considered (Table 1). For instance, in EA2-temp the atmospheric forcing has been calculated as in the control simulation except that air temperature and specific humidity are taken from the simulation EA2, with an annual mean SST increase averaged for the Baltic Sea of $\Delta \mathrm{SST}=+3.7^{\circ} \mathrm{C}$. The forcing fields in EA2-wind+runoff and EA2 are the same but in EA2-wind+runoff, air temperature and specific humidity are taken from the control experiment $\mathrm{C}$.

\section{RESULTS}

\subsection{Validation}

Eilola et al. (2009) thoroughly validated the results of the modified version (no.2) of RCO-SCOBI for 19691998. Here we will focus briefly on results of the reference version (no.1) and on differences between the 2 versions. Fig. A1 (in the Appendix) shows observed and simulated mean profiles of oxygen, phosphate and nitrate and the range of variability in the present climate at selected monitoring stations (see Fig. 1). The overall performance of the model is satisfactory. The horizontal and vertical gradients of oxygen and the limiting nutrients, phosphate and nitrate, are simulated correctly. However, there are systematic biases as well. In the deep sub-basins there is a tendency towards overestimation of oxygen concentrations, and consequent under- and overestimations of phosphate and nitrate concentrations, respectively. If the bottom oxygen concentrations increase, the sediment PRC will decrease causing decreasing phosphate concentra-

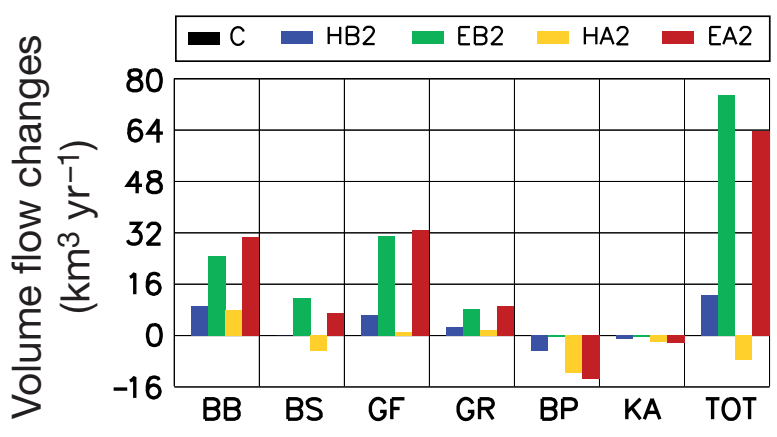

Fig. 3. Mean volume flow changes in the simulations HB2, EB2, HA2, and EA2, relative to the control simulation (C); see Table 1 for definitions. BB: Bothnian Bay; BS: Bothnian Sea; GF: Gulf of Finland; GR: Gulf of Riga; BP: Baltic proper; KA: Kattegat (excluding the River Göta Älv); TOT: total Baltic Sea (including Kattegat) 


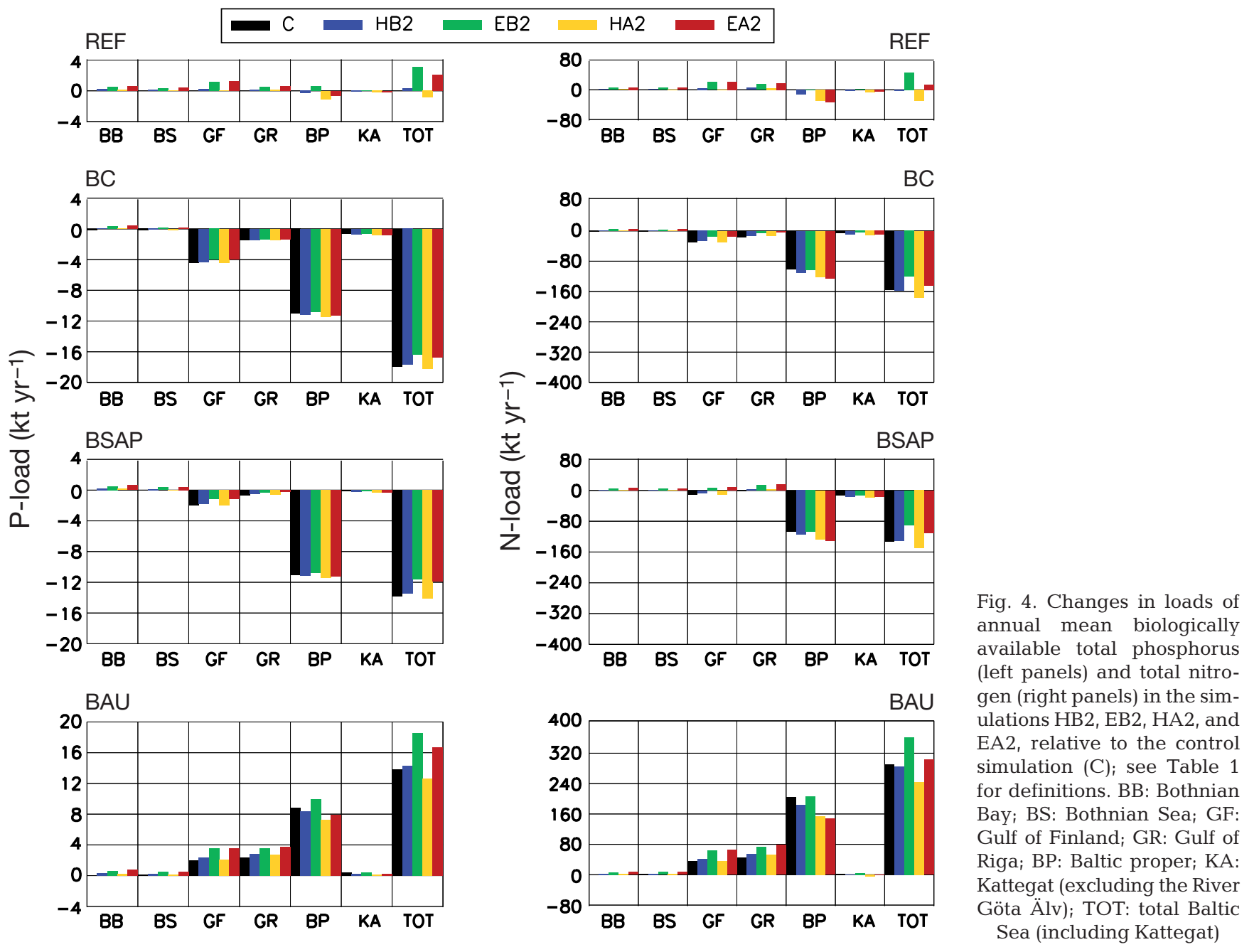

tions in the water column (Conley et al. 2002). Further, overestimation of oxygen concentrations would cause underestimation of denitrification, and consequent an overestimation of nitrate concentrations in the water column. The biases found are smaller in the results of Version 2 except in the Gulf of Finland where Version 1 shows better results (Eilola et al. 2009). Results for the Bothnian Sea and Bothnian Bay are not reliable (Eilola et al. 2010). In all RCO-SCOBI versions that use downscaled geostrophic wind as atmospheric forcing, the halocline depth in the deep sub-basins is underestimated, indicating that ventilation of the halocline layer is too intense (Meier et al. 2003, Meier 2006).

Horizontal distributions of mean surface layer DIN and DIP concentrations - vertically averaged for the upper $10 \mathrm{~m}$ and averaged for 1993-2002-are realistically simulated (not shown). As in observations, the simulated DIN to DIP ratio increases from the southern sub-basins (Arkona Basin, Bornholm Basin, and Baltic proper) towards the northern sub-basins (Bothnian Sea and Bothnian Bay) indicating that overall the ecosys- tem is roughly nitrate limited in the south and is roughly phosphate limited in the north (Table 3).

The comparison of the mean seasonal cycle of the total biovolume at Landsort Deep, a station located in the northwestern Gotland Basin (see Fig. 1), indicates that spring and autumn blooms are well reproduced by the model (Fig. 5). However, there are deviations at species level. The model does not show any cyanobacterial blooms at this station. Diatom blooms during autumn are also missing, while observations by Karl-

Table 3. With RCO-SCOBI simulated (C-REF-1) and observed ratio of dissolved inorganic nitrogen to phosphorus (DIN:DIP) vertically averaged for the upper $10 \mathrm{~m}$ (1969-1998) during winter (January and February). See Fig. 1 for location of monitoring stations (BY2, BY5, etc.)

\begin{tabular}{|lccccccc|}
\hline & BY2 & BY5 & BY15 & BY31 & LL07 & SR5 & F9 \\
\hline Observations & 7.6 & 6.8 & 7.9 & 7.6 & 10.0 & 16.7 & 226.9 \\
Model & 3.5 & 1.5 & 2.5 & 8.2 & 4.2 & 17.2 & 114.0 \\
\hline
\end{tabular}


son et al. (2010) indicate that during some years blooms may occur. However, the mean value of the observations is not representative for the period, because the autumn maximum is largely caused by 2 exceptionally large values that might be outliers. Thus, it is not possible to draw conclusions about the quality of simulated species concentrations. In Section 3.2, specific algal classes of the model will be discussed only as a means to understand model responses. We do not claim that our model has predictive capacity at the species level.

Although the spatial distributions of individual cyanobacterial blooms might be wrong, the internal
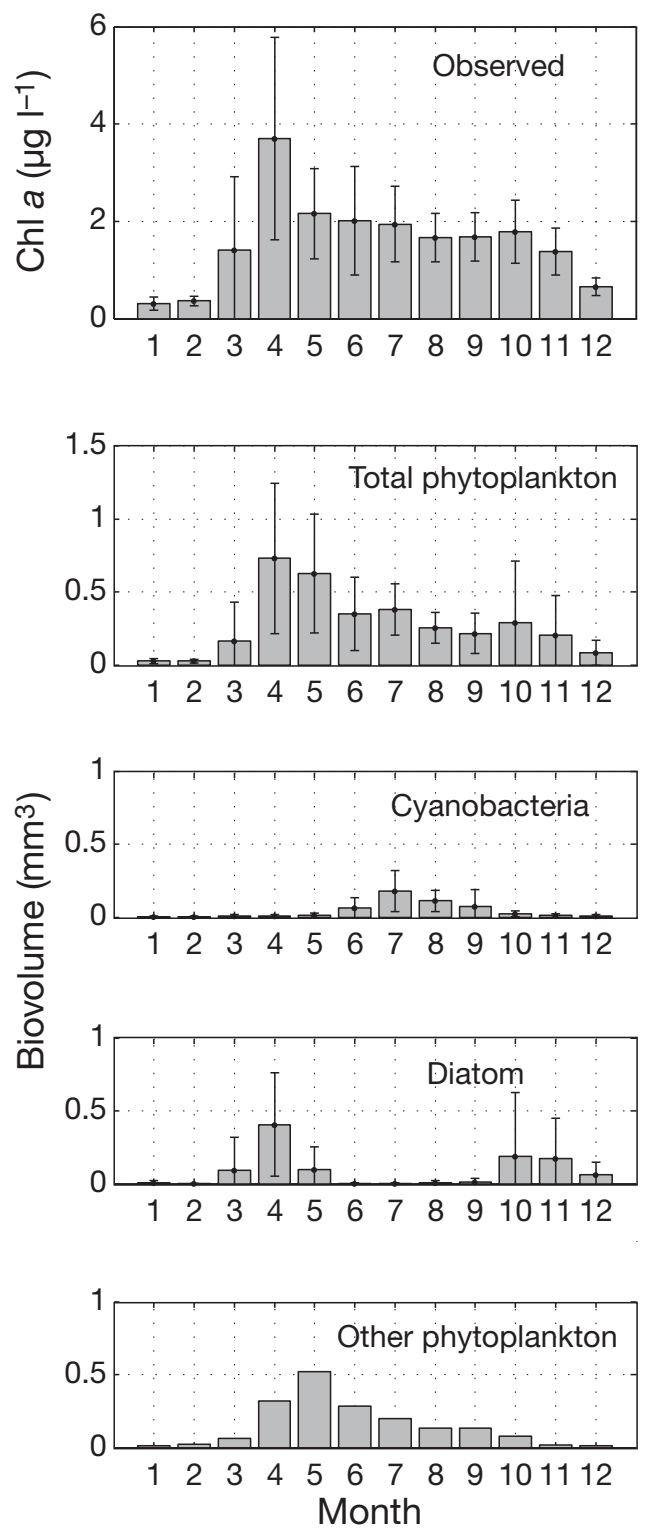

variability of the maximum surface area covered by cyanobacteria agrees reasonably well with estimates from satellite images (Fig. 6). During 1989 and 1990 the model appears to overestimate the cyanobacterial blooms. However the satellite observations are rather uncertain, due to the effect of clouds. Results by Kahru (1997) show large deviations between areas corrected for unequal number of available images and uncorrected areas. Despite these uncertainties, the model captures the minimum of the surface area during 1985-1988, as well as the subsequent increased cyanobacterial abundance during the 1990s.
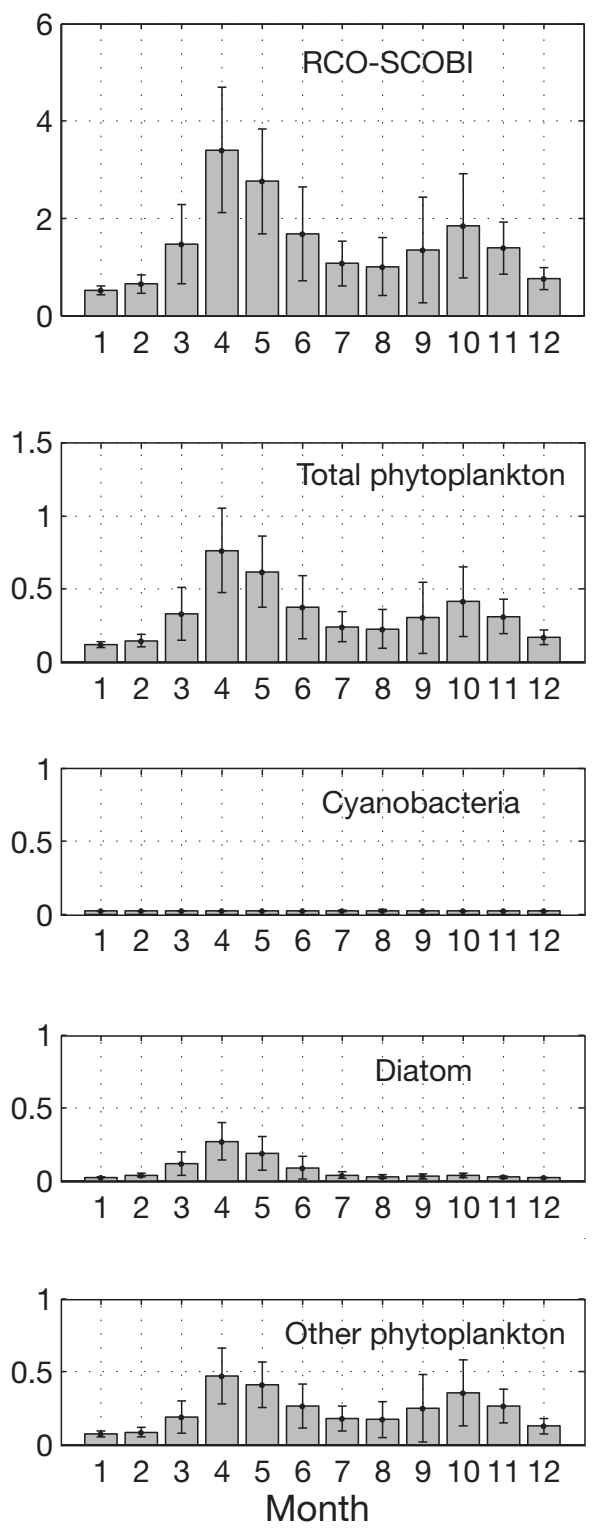

Fig. 5. Monthly chlorophyll a ( $\mathrm{chl}$ a) content and biovolumes of total phytoplankton, cyanobacteria, diatoms and other species including flagellates, in observations (1990-2007, left panels) and model data taken from C-REF-1 (1980-1998, right panels) at Landsort Deep (BY31). Location of the monitoring station in Fig. 1 


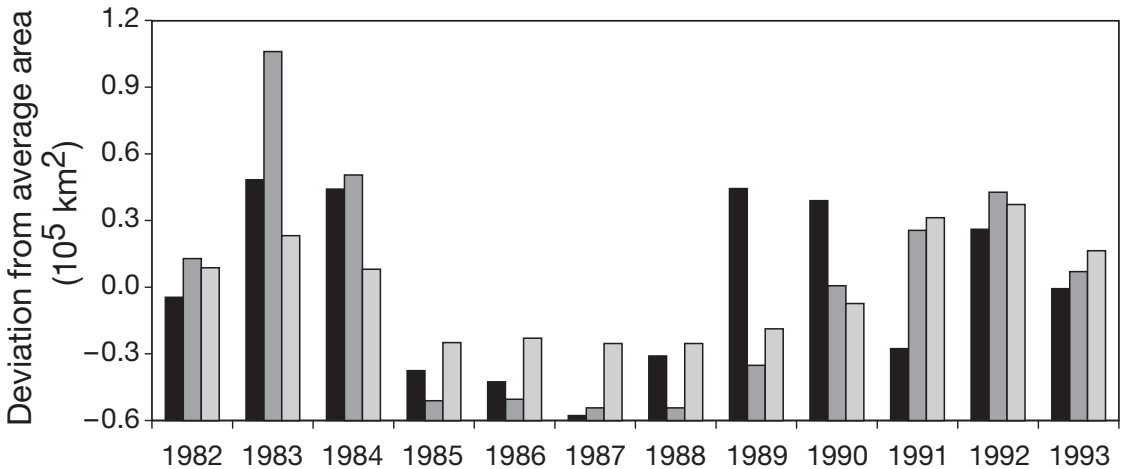

Fig. 6. Maximum surface area covered by cyanobacteria 1982-1993 in the Baltic proper. Model results from C-REF-1 (black), cumulative surface area estimated from satellite images (light grey) and the area corrected for unequal number of available images (dark grey; Kahru 1997)

\subsection{Simulations}

\subsubsection{Nutrient load changes}

In the 4 climate projections (HB2, EB2, HA2, and EA2), the total volume flows change, compared to the control simulation, with $+400,+2400,-200$, and $+2100 \mathrm{~m}^{3} \mathrm{~s}^{-1}$, corresponding to $+13,+76,-6$, and $+66 \mathrm{~km}^{3} \mathrm{yr}^{-1}$ (Meier 2006). Although these values differ substantially (between $-1 \%$ and $+17 \%$ of the annual mean volume flow in the control simulation of $14300 \mathrm{~m}^{3} \mathrm{~s}^{-1}$, corresponding to $451 \mathrm{~km}^{3} \mathrm{yr}^{-1}$ during 1961-1990), the spatial patterns in the catchment area are rather similar, with increased and decreased volume flows in the northern and southern subbasins, respectively (Fig. 3). This north-south gradient was also found when several differing regional climate models were used to downscale the climate change signal of the 2 driving GCMs used in this study (Graham et al. 2007). We found that the climate-induced nutrient load changes relative to the control climate (C) are smaller than the changes of the various nutrient load scenarios relative to the reference conditions (REF) (Fig. 4). Total nitrogen loads in HB2, EB2, HA2 and EA2 vary, relative to $C_{\text {, }}$ between -3 and $+5 \%$ applying $\mathrm{REF}$, between -14 and $-21 \%$ applying $\mathrm{BC}$, between -10 and $-18 \%$ applying BSAP, and between +28 and $+42 \%$ applying BAU. On the other hand the total nitrogen loads vary in the control climate between $-18 \%$ in C-BC and $+34 \%$ in C-BAU relative to C-REF. Corresponding values are found for total phosphorus loads. HB2, EB2, HA2 and EB2 vary, relative to $C$, between -3 and $+9 \%$ applying $\mathrm{REF}$, between -47 and $-52 \%$ applying $\mathrm{BC}$, between -33 and $-40 \%$ applying BSAP, and between +36 and $+53 \%$ applying BAU. Total phosphorus loads vary in the control climate between $-51 \%$ in $\mathrm{C}-\mathrm{BC}$ and $+53 \%$ in C-BAU relative to C-REF. Thus, in our ensemble of simulations, the effect of changing climate on the nutrient loads is smaller than the effect of changing nutrient loads due to altering land use, sewage water treatment, etc., because the largest increases of climate-induced volume flows (found in the ECHAM4 driven simulations) are confined to rivers in the northern sub-basins with relatively low nutrient concentrations, whereas net volume flow changes in the southern sub-basins, with relatively high nutrient concentrations, are smaller in relative terms.
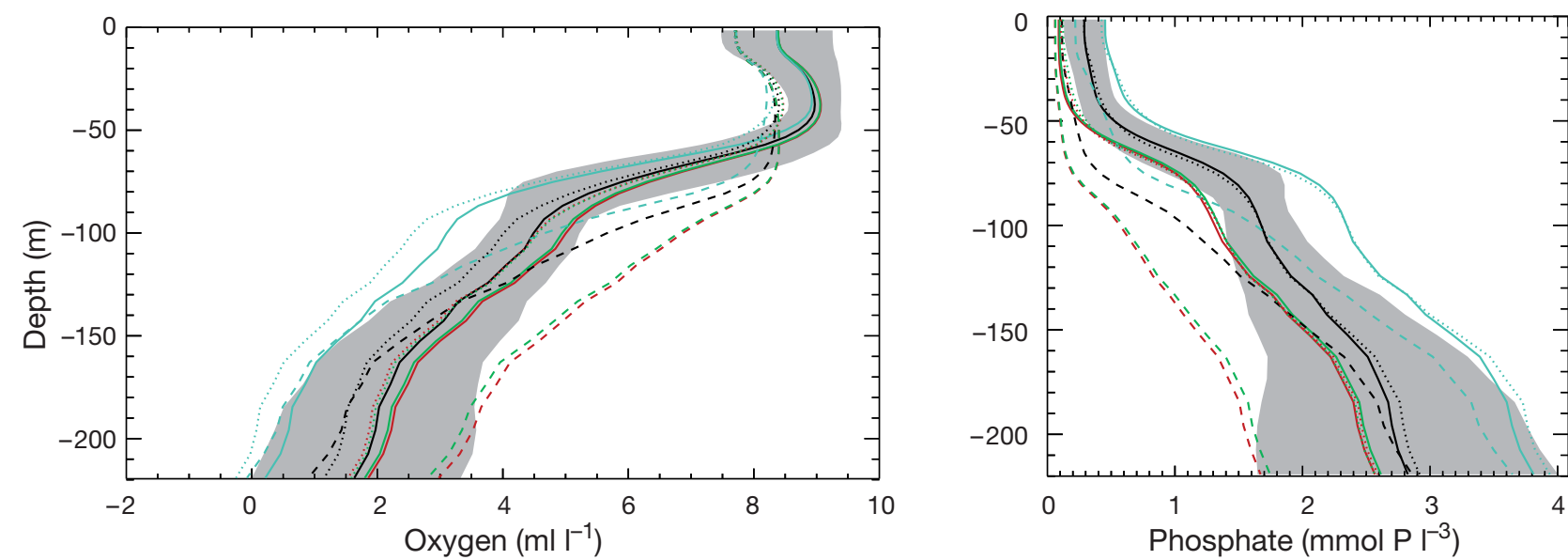

Fig. 7. (a) Oxygen and (b) phosphate profiles at Gotland Deep (BY15, see Fig.1). Reference conditions (REF: black) and nutrient load scenarios (BC: red, BSAP: green, BAU: blue) in the control (C: solid lines) and 2 future climates (HA2: dotted lines, EA2: dashed lines). Grey shading: range of variability indicated by \pm 1 SD calculated from REF. Results of the RCO-SCOBI model version 1 are shown. For abbreviations see Table 1 


\subsubsection{Oxygen and nutrient concentration changes}

Mean oxygen profiles at Gotland Deep and maps of bottom water oxygen concentrations are shown in Figs. $7 \& 8$, respectively. Negative oxygen concentrations correspond to hydrogen sulphide concentrations.

In nutrient load scenarios during the control period, oxygen concentrations in the surface layer above the permanent halocline are not significantly changed (not shown). However, below the halocline large changes, regionally up to $>2 \mathrm{ml}^{-1}$, are observed (Fig. 8, upper panels). In BC and BSAP, the deep layer oxygen concentrations are increased, especially in the northwestern Gotland Basin, the Gulf of Finland, the northeastern Bothnian Sea, and Gdansk Bay (Fig. 8, upper panels), whereas increases in oxygen concentrations in the eastern Gotland Basin is relatively modest (Fig. 7a). In BAU, bottom oxygen concentrations almost everywhere are lower than for C-REF-1, except in some shallow coastal areas that are ventilated vertically (Fig. 8, upper panels). In the eastern Gotland Basin the deep water oxygen concentration decreases in this scenario by $>1$ SD of the natural variability in the control simulation. The SD is relatively large, due to the intermittent saltwater inflows (Fig. 7a).

In all future climates of our ensemble (including EB2 and HB2 that are not shown) the oxygen concentration of the surface layer decreases as a function of temperature, but independently of the nutrient loads because of the lower oxygen saturation concentration of warmer water (Fig. 7a). In contrast, the deep water oxygen projections depend critically on the driving GCMs. In HA2 and HB2 the deep water oxygen concentration decreases because saltwater inflows transport less oxygen rich water into the deep water. The water of these inflows originates from surface water in the Baltic entrance area. Beside a few river mouth regions, there is one exception in the entrance of the Gulf of Finland, where bottom water oxygen concentrations increase (Fig. 8, see HA2). This is due to increased mixing, which is caused by slightly increased wind speeds during summer (Räisänen et al. 2004). In HA2-BC-1 and HA2-BSAP-1, this wind effect is reinforced by reduced oxygen consumption following the overall nutrient load reductions affecting principally the whole Gulf of Finland, but also the northwestern Gotland Basin. On the other hand, in HA2-BAU-1 the increased oxygen consumption, following the large increase in nutrient supply, overwhelms all mixing influence on oxygen. In the latter simulation, the bottom oxygen deficiency is increased in almost all areas of the Baltic Sea (Fig. 8), but in particular the northern Bothnian Sea, the area around Gotland Deep, the southern part of the Gulf of Riga and a smaller area south of the island of Bornholm.
In EA2 and EB2, increased mixing causes a significantly deeper halocline due to increased wind speeds during winter (Räisänen et al. 2004). Thus, in the depth interval between about 50 and $130 \mathrm{~m}$, oxygen conditions are improved (Fig. 7a). This oxygen increase also affects the bottom layer, and it is largest in the northwestern Gotland Basin and in the Gulf of Finland (Fig. 8, lower panels). In the Gotland Deep area, the bottom oxygen concentration decreases in EA2-REF-1 and EA2-BAU-1 but increases in EA2-BC-1 and EA2BSAP-1 (Fig. 7a). Thus, in the ECHAM4-driven simulations, we have the ambivalent situation of both decreased and increased bottom oxygen concentrations in the coastal areas and in larger parts of the deeper sub-basins, respectively.

As the internal loads of phosphorus from the sediments depend very critically on the bottom oxygen concentration, phosphate and oxygen concentrations in the deep water are to a high degree anti-correlated (Conley et al. 2002, Eilola et al. 2009). Thus, the changes of phosphate are relatively straightforward to predict. For instance, in EA2-BC-1 and EA2-BSAP-1, increased bottom oxygen concentrations cause decreased phosphate concentrations in the whole water column (Fig. 7b). In general, phosphate in the surface layer is renewed due to deep convection and Ekman pumping, mainly during winter (e.g. Janssen et al. 2004, Neumann \& Schernewski 2008). Thus, in all simulations driven by ECHAM4 (even in EA2-BAU-1), the surface phosphate concentration at Gotland Deep decreases (Fig. 7b).

\subsubsection{Phytoplankton concentration changes}

In the reference simulation, C-REF-1, the largest phytoplankton concentrations are found in the Gulf of Finland, Baltic proper and the Baltic entrance area, including the Kattegat. The biomass production in the coastal zones of these sub-basins is particularly large in comparison to the central parts of the sub-basins (Fig. 9).

In the nutrient load scenario simulations, changes in nutrient availability in the water column explain most of the changes of the annual mean phytoplankton concentrations in the surface layer. Thus phytoplankton concentrations are substantially lower in C-BC-1 and C-BSAP-1, and higher in C-BAU-1, compared to the reference simulation C-REF-1 (Fig. 9, upper panels).

This general pattern is also found in the future climate, independently of the driving GCM. The changes in the HadAM3H driven simulations are relatively small when the reference nutrient loads are applied (Figs. 9 \& 10). In Version 1, phytoplankton concentrations increase only in some parts of the coastal zone 

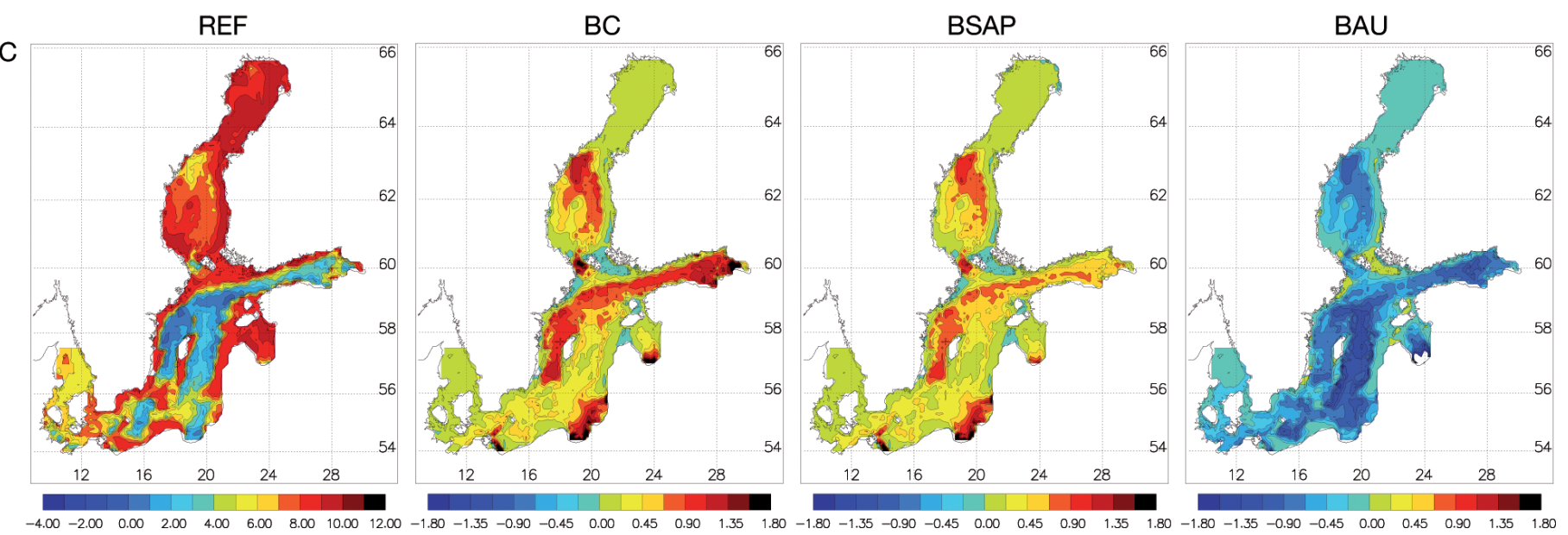

HA2
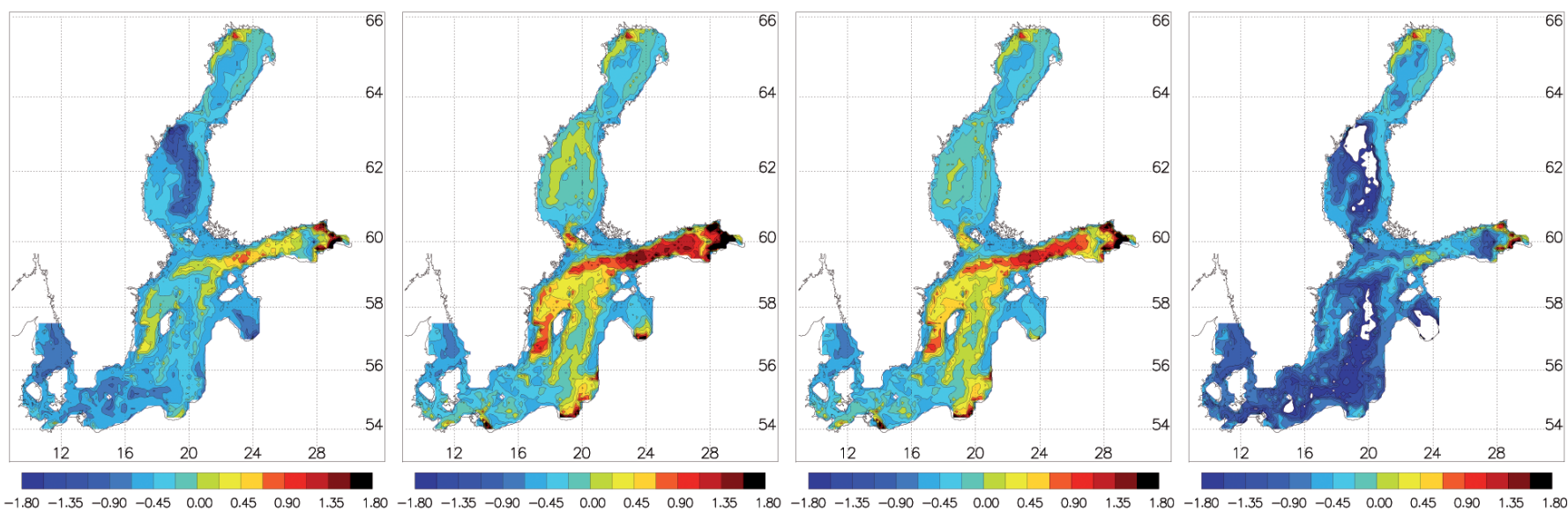

EA2
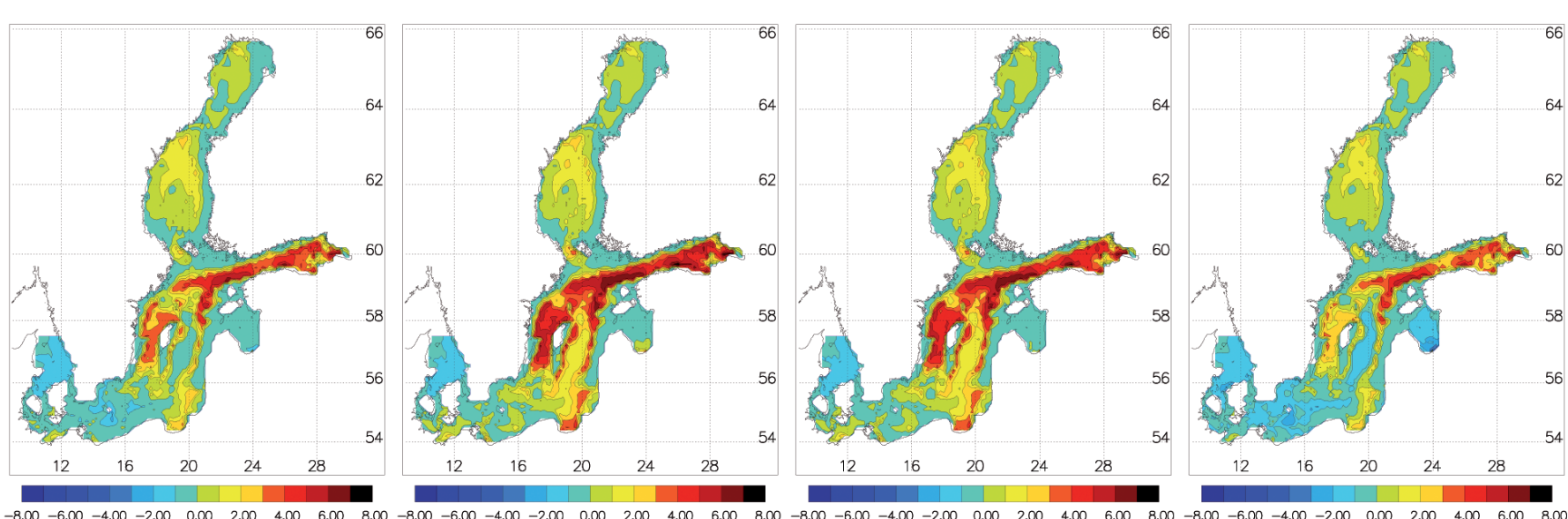

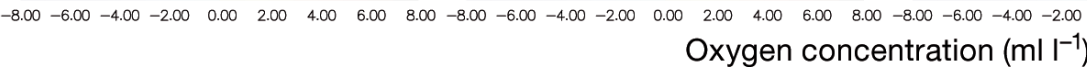

Fig. 8. Annual mean bottom oxygen concentration in C-REF-1 (upper left panel) and changes in the scenario simulations relative to C-REF-1: C (upper panels), HA2 (middle panels), EA2 (lower panels), REF (first column), BC (second column), BSAP (third column), and BAU (fourth column). Note that changes in the middle row $<-1.8 \mathrm{ml} \mathrm{l}^{-1}$ are depicted in white and that differing color bars for the results of HadAM3H and ECHAM4 driven simulations are used. Results of RCO-SCOBI model version 1 are shown.

Negative oxygen values correspond to hydrogen sulphide concentrations 

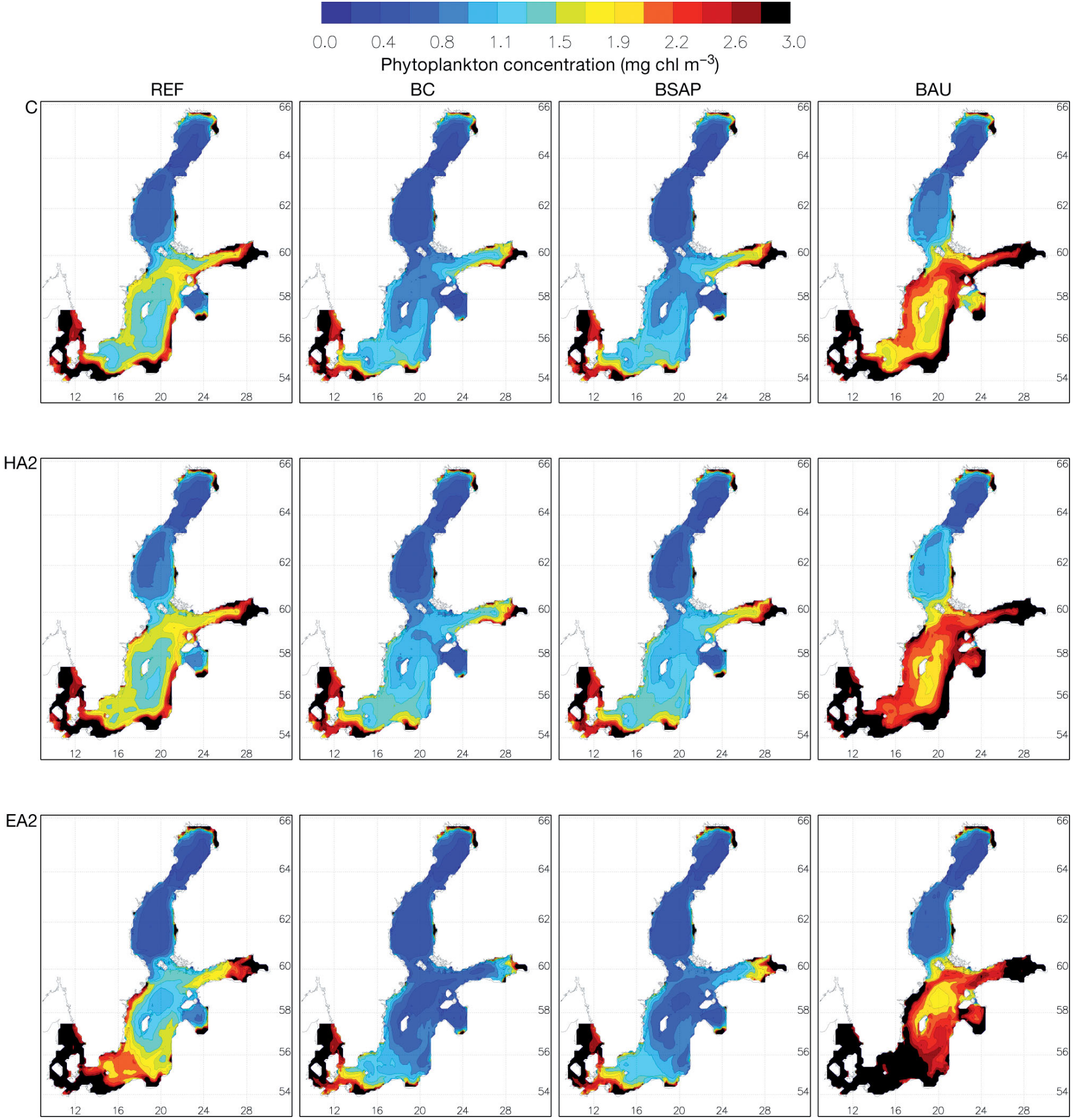

Fig. 9. Annual mean phytoplankton concentration, vertically averaged for the upper $10 \mathrm{~m}$ in the control (C-REF-1, upper left panel) and in the scenario simulations. Note that phytoplankton changes $>3.0 \mathrm{mg} \mathrm{chl} \mathrm{m}^{-3}$ are depicted in black 


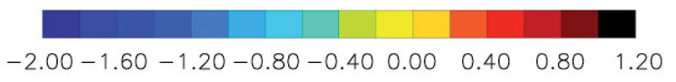

Phytoplankton change $\left(\mathrm{mg} \mathrm{chl} \mathrm{m}^{-3}\right)$
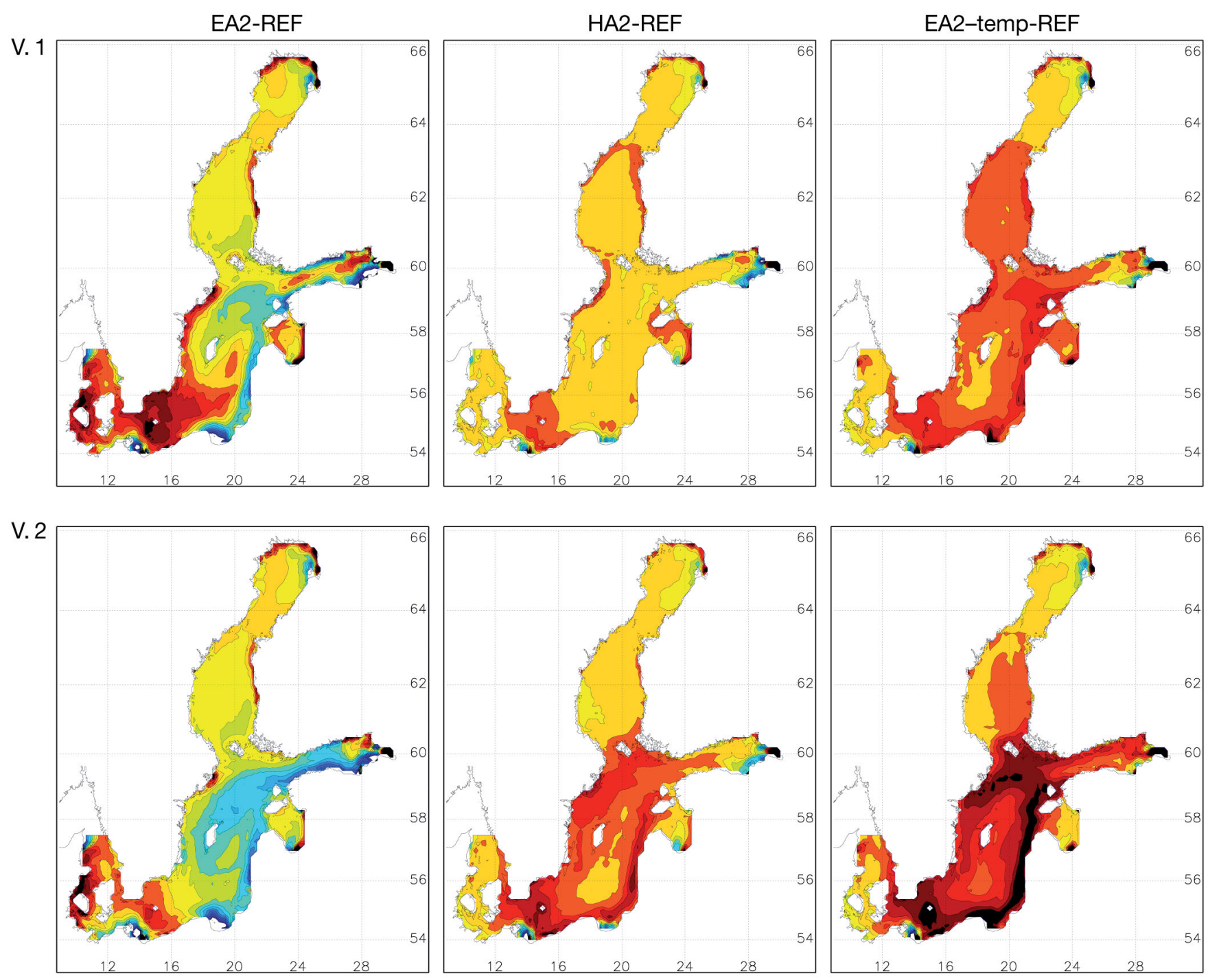

Fig. 10. Annual mean phytoplankton concentration changes vertically averaged for the upper $10 \mathrm{~m}$ in the simulations relative to C-REF: EA2-REF, HA2-REF, and in the sensitivity experiment, EA2-temp-REF, simulated with 2 versions of the sediment module (Version 1: upper panels, Version 2: lower panels). Note that phytoplankton changes $>1.0 \mathrm{mg} \mathrm{chl} \mathrm{m}^{-3}$ are depicted in black. See Table 1 for notation

and in the southern Baltic (Fig. 10). Due to the nutrient load reductions in HA2-BC-1 and HA2-BSAP-1, phytoplankton concentrations are significantly reduced compared to C-REF-1. However, in HA2-BAU-1, increased water temperatures together with the increased nutrient loads lead to significantly larger phytoplankton concentrations, as in C-REF-1 and CBAU-1 (Fig. 9).

In the ECHAM4 driven simulations, the patterns of phytoplankton concentration changes are different, with an increase (compared to the control) in the south- western Baltic and a decrease in the northern Gotland Basin along with the coastal zones of the eastern Baltic proper and eastern Gulf of Finland (Fig. 9, lower panels, and Fig. 10). If nutrient loads are reduced, as they are in EA2-BC-1 or EA2-BSAP-1, climate change will help to reduce algal abundance in the central and northern Baltic proper. However, in EA2-BAU-1, phytoplankton concentrations increase almost everywhere compared to C-BAU-1 (Fig. 9). In this case climate change significantly amplifies the effect of increased nutrient loads on phytoplankton production. 


\subsection{Cause-and-effect studies}

The response of the biogeochemical cycles is nonlinear. To study the processes that explain most of the model responses, we performed sensitivity experiments: (1) the consequences of higher water temperatures in the simulations were investigated; (2) we studied the combined effect of increased temperature, increased wind speed and reduced nutrient loads in the Baltic proper on the phytoplankton concentration changes in the ECHAM4 driven simulations.

If air temperature and specific humidity only are increased following the EA2 projection, the SST averaged for the entire Baltic Sea area will increase with
$\Delta \mathrm{SST}=+3.7^{\circ} \mathrm{C}$ (EA2-temp-REF-1 and EA2-temp-REF2 ). As a consequence, the phytoplankton concentrations will increase in the Baltic proper, Gulf of Finland and Bothnian Sea, and especially in the coastal areas of these sub-basins (Fig. 10). In the eastern and southern Baltic proper this phytoplankton concentration increase is partly explained by an increase in cyanobacterial concentration (Fig. 11). Cyanobacteria grow faster in warmer water, and the production will increase if there is still phosphate available in the surface layer in late summer, after the spring bloom. Another important aspect of the temperature-dependent phytoplankton concentration increase is explained by the parameterization of the PRC in the sediments.

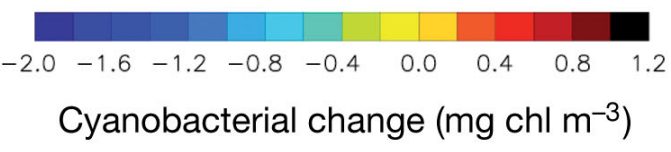

EA2-REF

V. 1

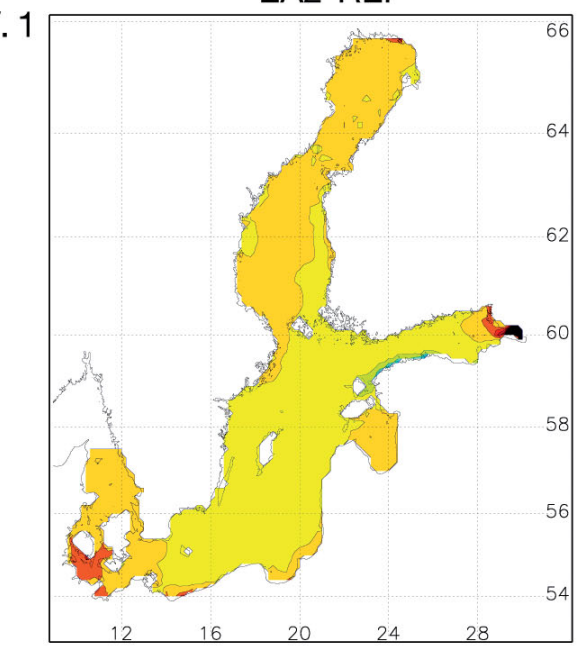

HA2-REF

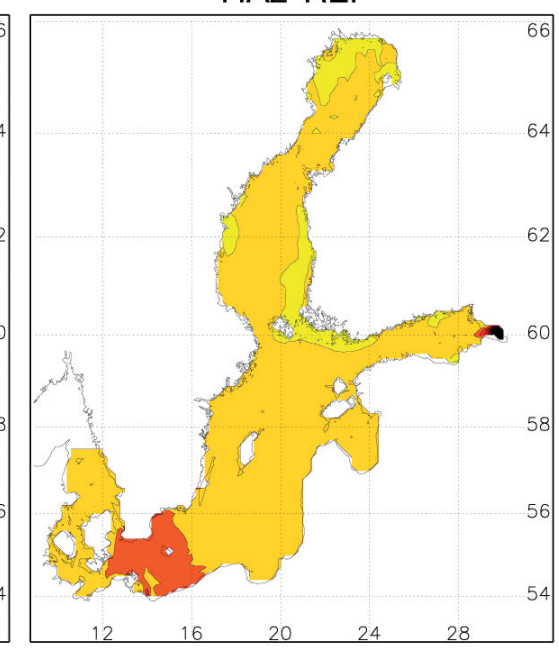

EA2-temp-REF

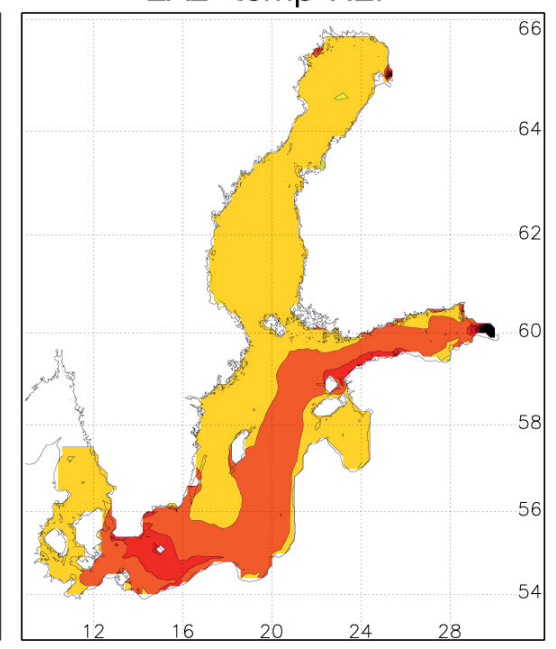

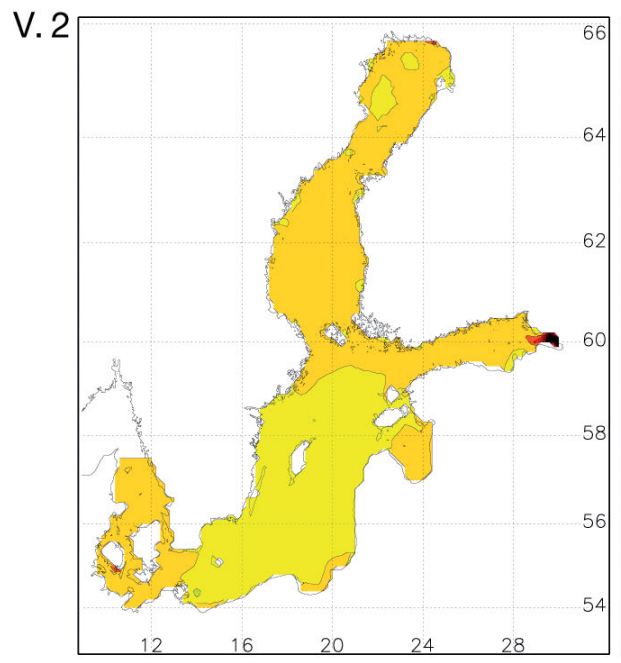
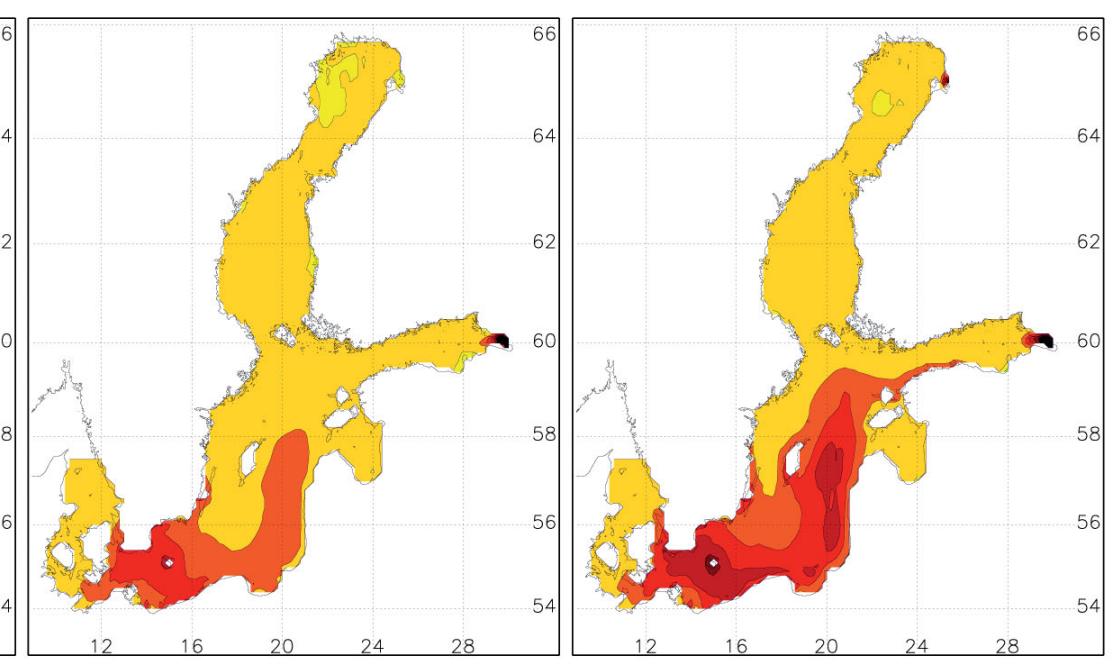

Fig. 11. As Fig. 10, but for annual mean cyanobacterial concentration changes, vertically averaged for the upper $10 \mathrm{~m}$ relative to C-REF. See Table 1 for notation 
In the model, the phosphorus fluxes increase with decreasing oxygen concentrations caused by increasing water temperature. In warmer water, the oxygen saturation-and consequently also both surface water and deep water oxygen concentrations - are lower. In the sediment module of version 2 of RCO-SCOBI (Eilola et al. 2009), changes in the PRC in the sediments are larger than in the reference Version 1 of this study, because the parameterization of the release capacity in Version 2 is more sensitive to changes of bottom oxygen concentrations than in Version 1. Consequently, we found larger increases of phytoplankton and cyanobacteria concentrations in warmer water in Version 2 (Figs. 10 \& 11).

In HA2-REF-1 and HA2-REF-2, the temperature effect is partly compensated by the decreased phosphorus and nitrogen loads in the Baltic proper (Fig. 4) resulting in smaller phytoplankton and cyanobacteria concentration increases (Figs. $10 \& 11$ ) than in the corresponding sensitivity experiments, HA2-temp-REF-1 and HA2-temp-REF-2 (not shown).

In the following, the more complex results found in the ECHAM4 driven simulations (Figs. 9-11) are discussed. The largest part of the annual mean phytoplankton concentration changes in EA2-REF-1 is related to concentration changes of flagellates during the spring bloom (Fig. 12a). In EA2-REF-1, the concentration of this group of species increases in the southern and central Baltic proper, including the Arkona Basin and Bornholm Basin. In addition, the Swedish east coast and some areas in the Gulf of Finland experience an increase in concentration of flagellates. A significant decrease in concentration is found in the down- welling areas along the east coast of the Baltic proper. Changes in diatom concentrations are qualitatively similar, but much smaller (not shown), because temperature dependency of the growth rate is larger for flagellates than for diatoms, and mean concentrations are larger in the model (Fig. 5).

In the sensitivity experiments, changes in wind speed in the ECHAM4 driven simulations (see EA2wind-REF-1) cause an overall decrease in concentration of flagellates during spring, except in the Arkona Basin and the Kattegat area (Fig. 12b). Additional nutrient load reductions in the Baltic proper (see EA2-wind+runoff-REF-1) do not significantly change the response during the spring bloom (Fig. 12c). On the other hand, the temperature increase following the EA2 projection (see EA2-temp-REF-1) significantly affects the concentration of flagellates in (principally) the northern Baltic proper and some coastal areas in the Baltic proper, the Gulf of Finland and the Gulf of Riga close to river mouths (Fig. 12d). Thus, none of the driving forces (wind-induced mixing, nutrient loads, water temperatures) alone can explain the simulated horizontal patterns of phytoplankton changes during the spring bloom in EA2-REF-1.

This finding is supported by the analysis of seasonal concentration changes of flagellates at the Bornholm Deep (BY5) station in the southern Baltic proper (Fig. 13). A strong increase of the spring bloom is only found in the EA2-REF-1 simulation (Fig.13a). Changes in wind-induced mixing (Fig. 13c) and changes of the water temperature (Fig. 13d) affect only the timing of the spring bloom with a delayed or earlier spring bloom, respectively.

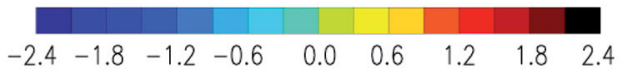

Flagellate change $\left(\mathrm{mg} \mathrm{chl} \mathrm{m}^{-3}\right)$

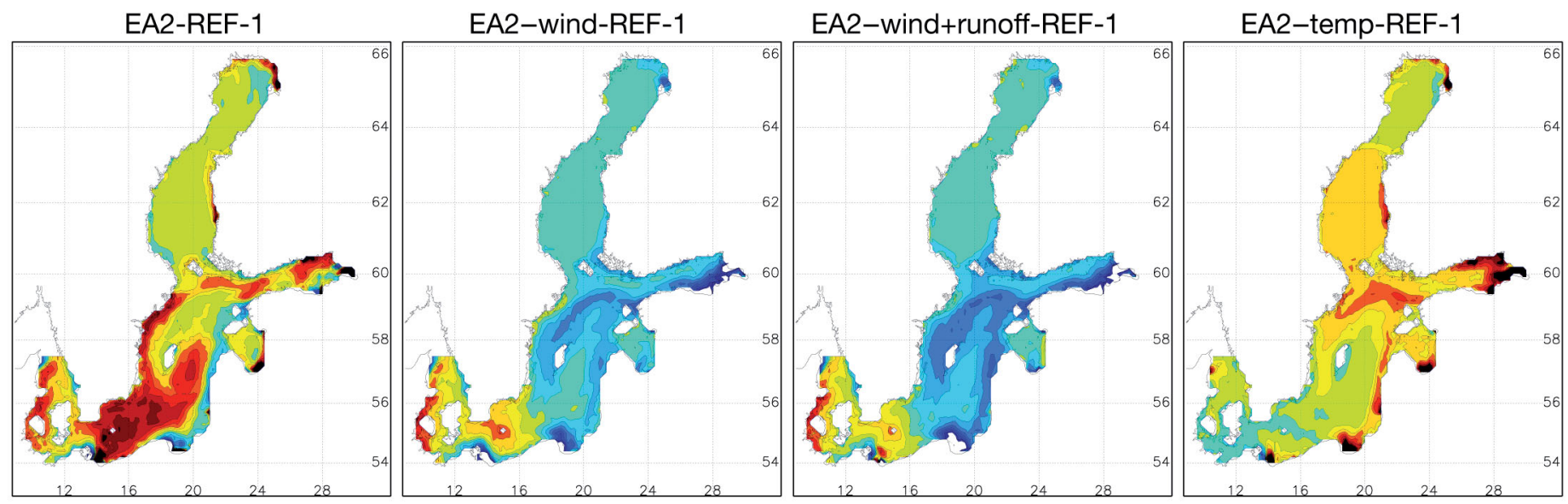

Fig. 12. Spring (March through May) mean concentration changes of flagellates vertically averaged for the upper $10 \mathrm{~m}$ relative to C-REF-1. See Table 1 for notation 


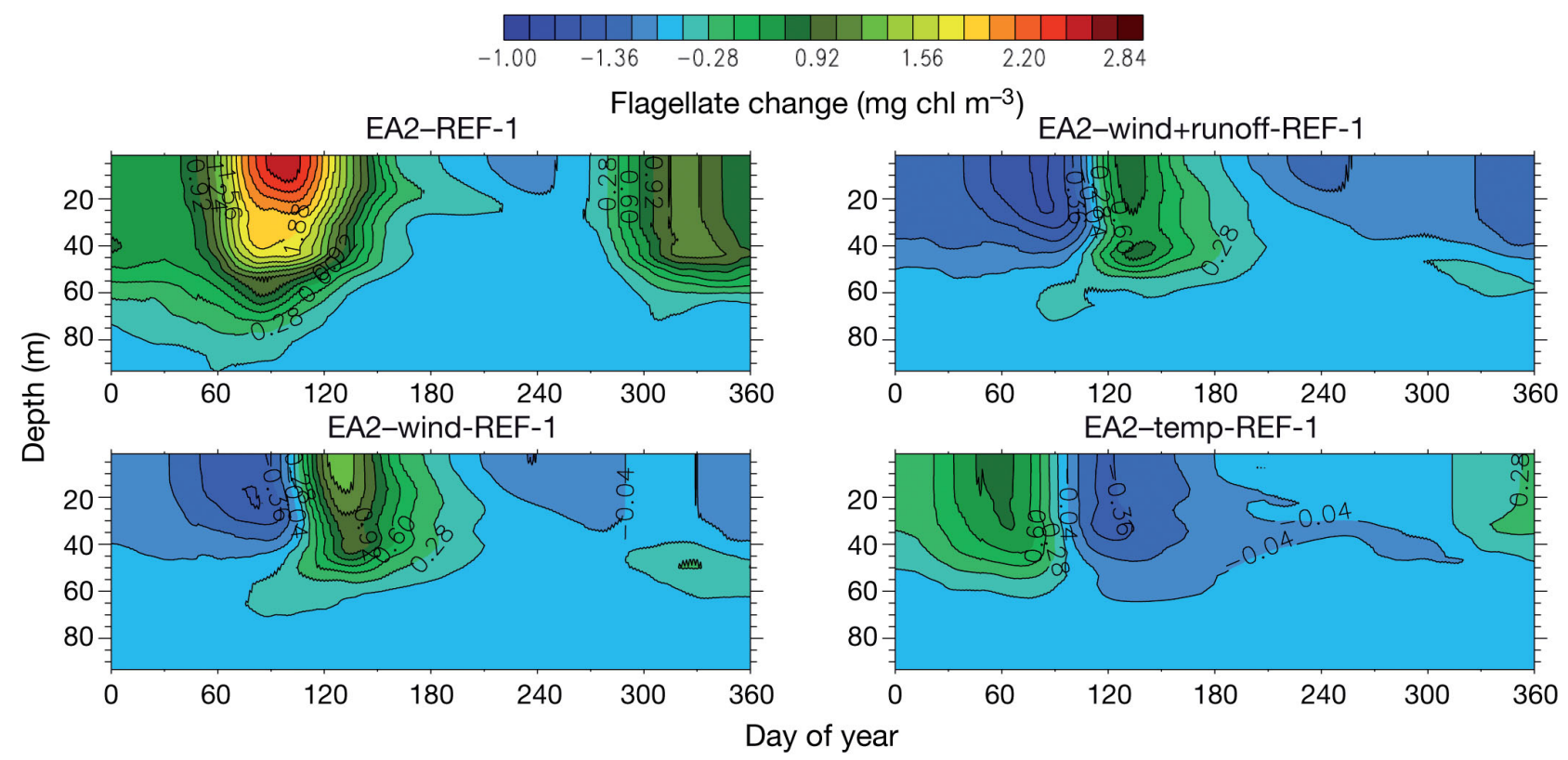

Fig. 13. Seasonal concentration changes of flagellates and other species as a function of depth at Bornholm Deep (BY5, see Fig. 1) relative to C-REF-1. The panels show, from upper-left to lower right, results from the scenario and sensitivity experiments. See Table 1 for notation

In the ECHAM4-driven projection, EA2-REF-1, the monthly mean wind speed during February increases by $30 \%$ or more (Räisänen et al. 2004), causing a deeper halocline due to increased wind-induced mixing (Meier, 2006). As a consequence salt water inflows entrain more oxygen-rich water, causing increases in oxygen concentrations in the deep water below the halocline (Fig. 7a). Higher oxygen concentrations in the bottom water affect the internal phosphorus loads from the sediments, as mentioned earlier (Fig. 7b).
Thus, a consequence of increased wind-induced mixing is that during winter, before the spring bloom, phosphate concentrations in the surface layer are reduced (Fig. 14b). Although higher water temperatures cause reduced oxygen concentrations in the bottom waters, and increased phosphorus fluxes from the sediments (Fig. 14d), the effect is in this case overshadowed by increased wind mixing. The deepening of the halocline increases oxygen concentrations deeper in the water column, and decreases phosphorus fluxes

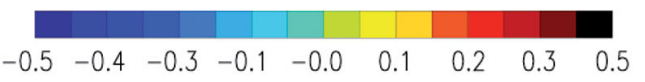

Phosphate change ( $\mathrm{mmol} \mathrm{P} \mathrm{\textrm {m } ^ { - 3 } )}$

EA2-REF-1

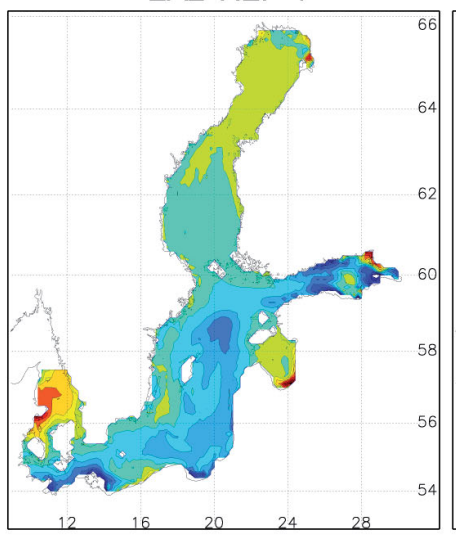

EA2-wind-REF-1

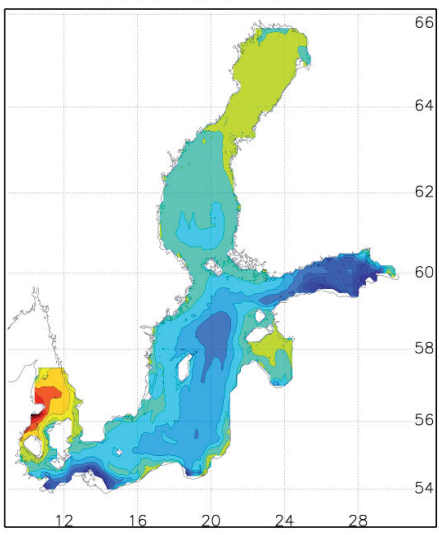

EA2-wind+runoff-REF-1

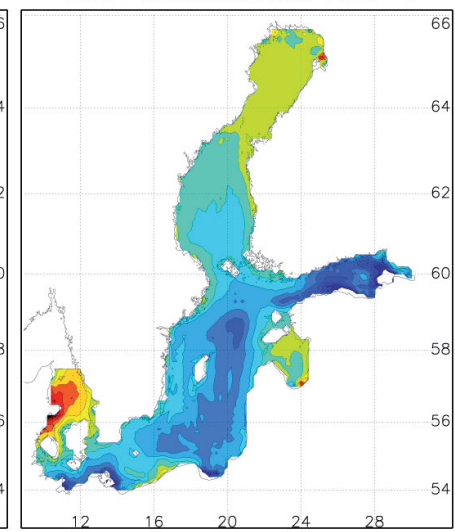

EA2-temp-REF-1

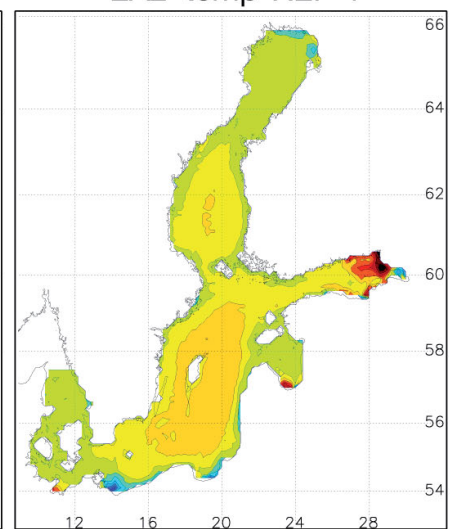

Fig. 14. Winter (December through February) mean phosphate concentration changes vertically averaged for the upper $10 \mathrm{~m}$ relative to C-REF-1. The panels show from left to right results from the scenario and sensitivity experiments. For the notation see Table 1 

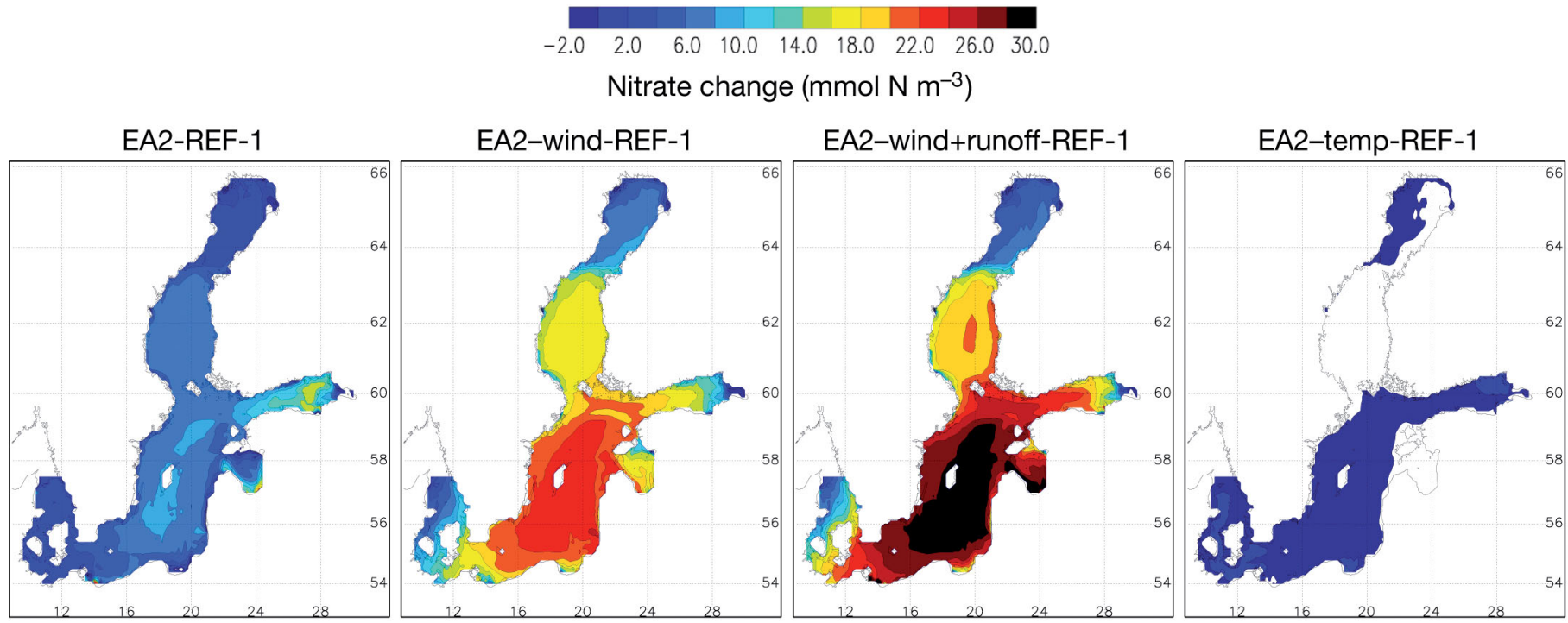

Fig. 15. Winter (December through February) mean nitrate concentration changes vertically averaged for the upper $10 \mathrm{~m}$ relative to C-REF-1. The panels show from left to right results from the scenario and sensitivity experiments. Note that changes smaller than $-2.0 \mathrm{mmol} \mathrm{N} \mathrm{m}^{-3}$ are not depicted and that changes larger than $28.0 \mathrm{mmol} \mathrm{N} \mathrm{m}^{-3}$ are depicted in black

from the oxidised sediments (Fig. 7b). Thus, higher water temperatures have-in addition to increased mixing - only a small impact on the surface DIP concentrations (Fig. 14a).

Another effect of increased oxygen concentrations in EA2-REF-1 is a reduction of denitrification causing a strong increase of nitrate in the surface water (Fig. 15a). Note that at the sea surface, nitrate and DIN maps are almost identical (not shown). In all experiments nitrate concentration changes are mainly explained by denitrification changes in the sediments (referred to as benthic denitrification hereafter). Denitrification in the model is mainly driven by the decomposition of organic matter in the sediments (Eilola et al. 2009). Since oxygen is the primary electron acceptor, decomposition is only partly carried out by denitrifying bacteria when oxygen is abundant in the water overlying the model sediments. During high oxic conditions $\left(\mathrm{O}_{2}>\sim 7 \mathrm{ml} \mathrm{l}^{-1}\right)$ $60 \%$ of the mineralized ammonium is recycled to the water as $\mathrm{NO}_{3}$ while the rest $(40 \%)$ is denitrified. The denitrified fraction increases for declining oxygen concentrations below $7 \mathrm{ml} \mathrm{l}^{-1}$, and has its maximum of almost $100 \%$ in the range 0 to $1 \mathrm{ml} \mathrm{l}^{-1}$. Under anoxic conditions, denitrification may only take place if nitrate is available in the water overlying the sediment. With the present loading the nitrogen concentrations may increase to $>60 \mathrm{mmol} \mathrm{m}^{-3}$ in the Baltic proper if the biogeochemical sinks (mainly denitrification) are turned off in RCO-SCOBI. This causes a considerable oxygen dependence of nitrogen concentrations in the model.

As increased water temperature causes decreased oxygen concentration, the deep water suffers from oxygen deficiency with increased denitrification, ac- cording to our parameterization. Thus, in EA2-tempREF-1, surface nitrate concentration decreases (Fig. 15). Changing external nitrogen loads (see EA2-wind +runoff-REF-1 compared to EA2-wind-REF-1) and water temperatures (EA2-temp-REF-1) have a smaller effect on surface nitrate concentrations in winter compared to the effect of wind induced mixing (EA2-windREF-1). In EA2-wind+runoff-REF-1 the nitrate concentrations increase in the Baltic proper compared to EA2-wind-REF-1 (Fig. 15) because nutrient loads (Fig. 4) and surface layer phosphorus concentrations (Fig. 14) are reduced, causing reduced phytoplankton production, reduced decomposition, increased oxygen concentrations and consequently reduced denitrification.

Higher water temperatures cause earlier spring blooms in the southern Baltic, where light is not limiting (Fig. 13d). However, if the nutrient concentrations in the water column do not change, the spring bloom will start earlier but will not necessarily become more intense. Stronger mixing in winter and early spring delays the spring bloom with (Fig. 13b) and without changing nutrient loads (Fig. 13c).

As in the southern Baltic, nitrate limits the duration of the spring bloom in the model. Higher nitrate concentrations in the surface layer cause higher concentrations of phytoplankton. This is the case when both water temperature and wind-induced mixing increase simultaneously as in EA2-REF-1 (Figs. 12a \& 13a). In addition to the increase of available nitrate in an otherwise nitrate-limited region, the longer potential blooming period may contribute to higher annual mean phytoplankton concentrations. In the simulations, April and May are warmer than in the present climate. The 

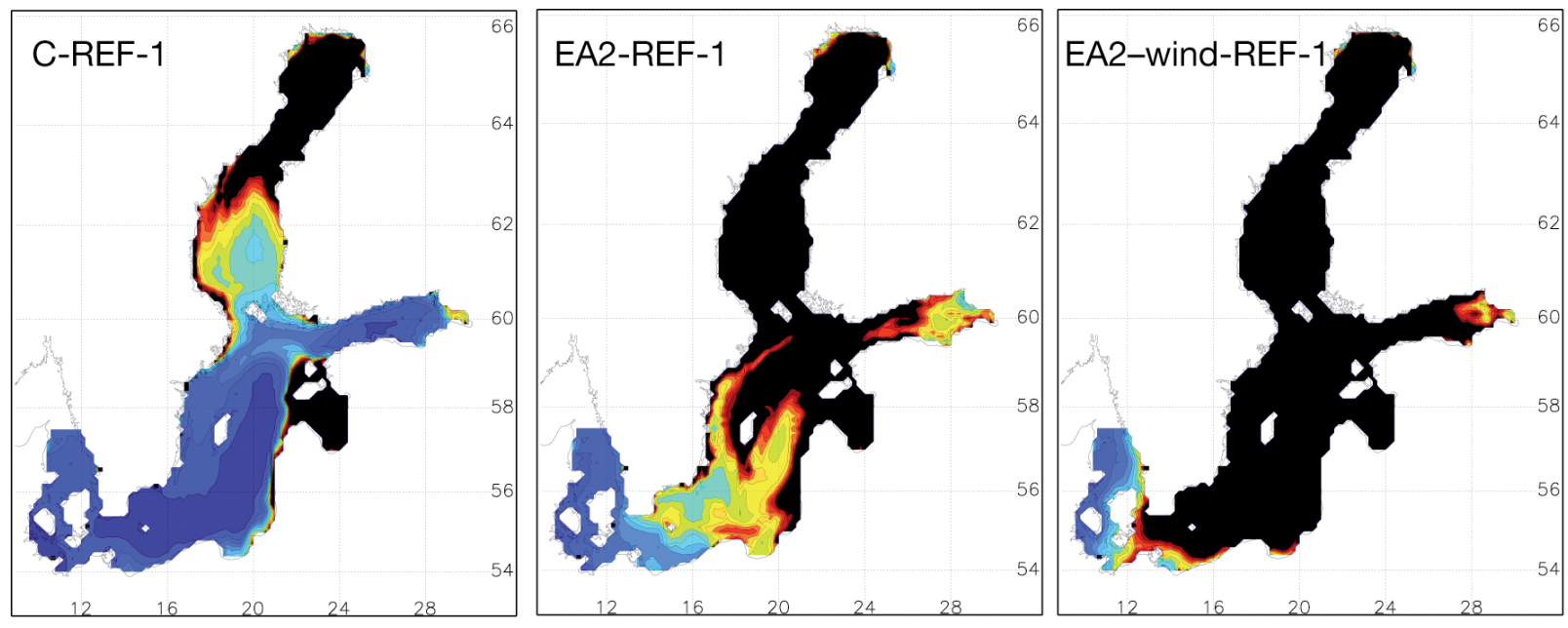

$\begin{array}{lllllllll}0.0 & 8.0 & 16.0 & 24.0 & 32.0 & 40.0 & 48.0 & 56.0 & 64.0\end{array}$

DIN:DIP

Fig. 16. Winter (December through February) mean DIN:DIP ratio vertically averaged for the upper $10 \mathrm{~m}$. Result from present climate and reference nutrient loads (C-REF-1) and from left to right results from the scenario and sensitivity experiments. For the notation see Table 1. Note that ratios larger than 60 are depicted in black

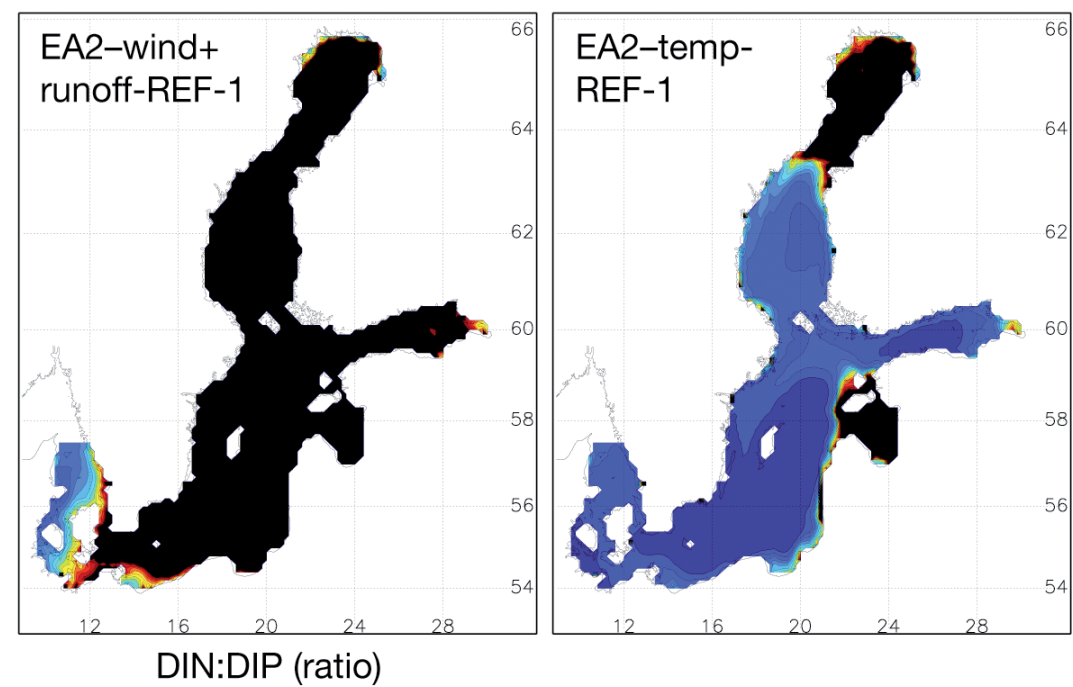

reduction in surface phosphate concentration in EA2REF-1 relative to C-REF-1 does not reduce the spring bloom intensity here, because the winter phosphate concentration is still so high that it does not limit biomass production.

In the central northern Baltic proper the concentration of flagellates does not change significantly in EA2REF-1 relative to C-REF-1 (Fig. 12a), and the total phytoplankton concentration even decreases (Fig. 10), even though more nitrate is available (Fig. 15a). However, in this case phosphate is limiting (Fig. 14a). The ratio of DIN:DIP does not favour increasing concentrations of flagellates in EA2-REF-1 (Fig. 16b) relative to C-REF-1 (Fig. 16a). In the model the DIN:DIP winter ratio increases in the Baltic proper due to the mixing effect (Fig. 16c). Although in the present climate, excess phosphate increases with depth, in our simulations mixing does not decrease the DIN:DIP ratio, because the assumed mixing is so strong that even bottom oxygen concentrations will change, affecting both benthic phosphorus fluxes and benthic denitrification.
Hence, during winter, DIP will decrease and DIN will increase resulting in an increased DIN:DIP ratio (Fig. 16c). Increased water temperatures alone would cause a reduced DIN:DIP ratio (Fig. 16e) and a somewhat higher concentration of flagellates in the northern Baltic proper (Fig. 12d). However, in this scenario (EA2-REF-1) the effect of increased wind-induced mixing on the surface concentrations of DIN and DIP is stronger than the effect of increased water temperatures (Fig. 16b).

In summary, the following drivers and their interactions explain the modelled changes in the ECHAM4 driven simulations with increased temperature, increased wind induced mixing, and reduced nutrient loads in the Baltic proper:

(1) Increased mixing causes increased oxygen below the halocline and reduced winter DIP and reduced benthic denitrification (i.e. increased DIN) (Figs. 7, 8, 14b, 15b).

(2) Increased water temperatures cause earlier spring blooms and (at least slightly) more intense cyanobacteria blooms (Figs. 11 \& 13d). 
(3) Increased temperatures together with increased mixing in the western Baltic cause enhanced spring blooms of flagellates because of an increase of available nitrogen in an otherwise nitrogen-limited region, and very likely because of a longer potential blooming period (warmer April and May) (Figs. 12a \& 13a).

(4) In the northern Baltic proper, the concentration of flagellates does not change significantly in the EA2REF-1 simulation, due to limiting phosphate concentrations (temperature and mixing effects cancel each other) (Figs.12a \& 16b).

(5) In future climates, the projected reductions of river-borne nutrient loads calculated from contemporary concentrations in the Baltic proper have only a minor effect on phytoplankton changes (Fig. 12c compared to Fig. 12b).

\section{DISCUSSION}

This study is the starting point of a major effort to calculate the combined effect of changing climate and nutrient loads (the latter caused by changing human activity) on the Baltic Sea ecosystem (e.g. www.baltexresearch.eu/ecosupport). In the following we discuss some potential shortcomings that could have an effect on our results.

The sensitivity of the model response to changing climate depends on key processes that are not well understood. In particular, more research on 2 processes is needed, because they are mainly responsible for the calculated sensitivity in our model: (1) the phosphorus fluxes between the water column and the sediments and (2) benthic denitrification. In addition to the parameterization of the phosphorus fluxes, the vertical distribution of the phosphorus sediment pools at the slopes with maxima in depth ranges of between 30 and 70 m (Carman \& Cederwall 2001) could be improved. For the model response the location of the maxima of benthic phosphorus relative to the redoxcline is important. In the present version, a wave model is still missing. The role of waves is to transport sediments, with the help of resuspension, from shallow coastal productive zones into areas with greater water depth, where the influence of the waves ceases. In the Baltic Sea, sediment at depths as great as $80 \mathrm{~m}$ may be affected by wave-induced resuspension at least once a year (Jönsson et al. 2005). This process is not properly accounted for in the present model version.

The parameterization of denitrification, as well as of the burial of adsorbed ammonium under anoxic conditions, will be improved upon when more observational measurements from the Baltic sediments become available.

Furthermore, the microbial food web is not fully included (Eilola et al. 2009), and only the mineraliza- tion processes caused by microbial organisms are simulated. Consequently, phytoplankton production in the phosphorus limited northern Baltic proper may not be well described in EA2-REF-1, since the relative distribution of bacterial- versus phytoplankton-based production may change under different light conditions (e.g. Berglund et al. 2007). It has also been shown that the dynamics of inorganic nutrients in the Bothnian Bay cannot be described by the 'standard Redfield ratio' organic matter composition model used here (Eilola 2009). The effect of the microbial loop on DIN and DIP, as well as the parameterization of nitrogen fixation in the model, is however still unclear, since it would also incorporate dissolved organic matter into the seasonal cycles of nutrients. This could then have an effect on total production, as well as on cyanobacteria production.

As the carbon cycle is not included in the approach presented, another possible important effect - the acidification of the sea-is not considered (e.g. Raven et al. 2005, Omstedt et al. 2009). Acidification of the oceans is an emerging threat to marine ecosystems. Decadal records of $\mathrm{pH}$ in the Baltic Sea show acidification proceeding at rates 2 to 5 times faster than in the open ocean (Andersson et al. 2008). The effects of these changes and their interaction with other climate variables in mediating both gradual and state-shifts in marine ecosystems are likely to be considerable. Perhaps the greatest impact of acidification will be the reduced capacity of many marine species to build calcareous skeletons and shells that are essential for their survival. This will be a particular problem for microscopic plankton and larval stages, having direct effects on reproductive success and survival in key ecosystem-structuring species within the Baltic Sea, such as blue mussels.

Projected temperature and salinity changes may also have effects on species distributions, growth and reproduction of organisms at trophic levels higher than those explicitly resolved in our model, including zooplankton, benthos and fishes. These changes could include the loss of entire species, and major restructuring of the food web and of trophic flows. For example, decreasing salinity may prevent cod reproduction. Assuming top-down control in the marine food web, this would also have impacts on phytoplankton concentrations.

In addition to better descriptions of biogeochemical processes, the physical part of the dynamical downscaling approach needs to be improved. Instead of the time-slice approach following Meier (2006), transient simulations from the present climate until the end of this century are needed. This would avoid difficulties involved in deciding future initial conditions for simulations of salinity, and the need for the delta approach as described in Section 2.1. 
The nutrient load scenarios in this study are calculated from the product of changing nutrient concentrations on land in the present climate and changing volume flows in future climates. This approach does not take into account such factors as the effects of changing climate on land-surface vegetation, population density (including possible northward migration of people in a warmer climate), agriculture, nutrient point sources, and socio-economic adaptation processes to changing climate.

Further, assumptions of unchanged atmospheric deposition might be wrong. Langner et al. (2009) investigated one climate change scenario using nitrogen emissions for the year 2000. They found only a small impact on total deposition of nitrogen due to climate change. According to Langner et al. (2009), total nitrogen deposition may increase by $\sim 5 \%$ by the end of the 21st century as compared with present conditions. However, studies on future emissions, including effects on the Baltic Sea region, are not yet available.

The list of processes that are insufficiently described or not considered may actually be even longer. However, it is still possible to draw some conclusions from this study (as shown below). The uncertainty of the projections due to biases of the coupled physicalbiogeochemical model for the Baltic Sea could be reduced by applying a multi-model ensemble approach, as planned for the ongoing project, ECOSUPPORTAdvanced modeling tool for scenarios of the Baltic Sea ECOsystem to SUPPORT decision making (www. baltex-research.eu/ecosupport).

Although this study focuses on the marine environment of the Baltic Sea, the dynamical downscaling approach can easily be applied to any other regional sea. It can be used to study the combined effect of changing climate and eutrophication in general. Eutrophication is a global problem, not just a threat specific to the Baltic Sea. The distribution of eutrophication-associated dead zones matches the global human footprint in the Northern Hemisphere (Diaz \& Rosenberg 2008). The number of dead zones has increased world-wide during the past decades. According to Diaz \& Rosenberg (2008, p. 929), 'Further expansion of dead zones will depend on how climate change affects water-column stratification and how nutrient runoff affects organic matter production'.

\section{CONCLUSIONS}

(1) Projections of future climate suggest that water temperature will increase and ice cover will decrease.

(2) In addition, salinity may be unchanged or may decrease, with reduced stability and a deeper halo- cline. The uncertainties caused by the driving GCMs are considerable.

(3) Oxygen concentrations in the surface layer may decrease due to increased water temperature. Thus, saltwater inflows will transport less oxygenated water to greater depths, intensifying oxygen deficiencies in Baltic deep water.

(4) The sensitivity of the highly non-linear biogeochemical response to climate change depends on key processes that are not well understood (e.g. the functioning of the integrated sources and sinks in Baltic Sea sediments) and that act at long time scales. Thus, large uncertainties are also caused by the biogeochemical models.

(5) In the southwestern Baltic, phytoplankton concentrations may increase, and there is a risk that cyanobacteria blooms will become more intense.

(6) Future nutrient loads are uncertain, due to unknown agricultural practices, sewage water treatment, and other anthropogenic factors. Climate-induced changes of nutrient loads have a smaller impact on the modelled phytoplankton development than changes in socio-economic scenarios - ranging from the 'most optimistic' case (the Baltic Sea Action Plan, BSAP) to a pessimistic BAU scenario. However, this conclusion does not apply for bottom oxygen concentrations.

(7) The efficiency of the implementation of the BSAP may differ in future climates. However, the BSAP will likely reduce phytoplankton concentrations in future climates. This is a common result in all our simulations.

(8) The scenario of 'business-as-usual' in agricultural practices may have greater effects on the marine environment in future climates, with higher phytoplankton concentrations than in the present climate. This is a common result, even when bottom oxygen concentrations increase regionally.

Acknowledgements. This work was funded by the Swedish Research Council for Environment, Agricultural Sciences and Spatial Planning (FORMAS), the Swedish Environmental Protection Agency (Naturvårdsverket), and the BONUS + programme (www.bonusportal.org). One of the 16 funded BONUS+ projects is ECOSUPPORT (Advanced modeling tool for scenarios of the Baltic Sea ECOsystem to SUPPORT decision making, ref.no. 08/381) which supported this study. The RCO-SCOBI model simulations were partly performed on the climate computing resource 'Tornado', operated by the National Supercomputer Centre at Linköping University. Tornado is funded by a grant from the Knut and Alice Wallenberg foundation. The model was forced with data from Swedish Meteorological and Hydrological Institute (SMHI) and the BED at the Baltic NEST Institute at Stockholm University. Monitoring station data used for the model validation are taken from the Swedish Oceanographic Data Center at SMHI (SHARK). We thank our colleague Bengt Karlson (SMHI) for preparing phytoplankton data at species level, and the anonymous reviewers for very useful comments that helped to improve the manuscript. 


\section{LITERATURE CITED}

Andersson P, Håkansson B, Håkansson J, Sahlsten E, Havenhand J, Thorndyke M, Dupont S (2008) Marine acidification: on effects and monitoring of marine acidification in the seas surrounding Sweden. SMHI Report Oceanografi nr.92. BACC author team: Assessment of climate change for the Baltic Sea Basin series. Regional Climate Studies, Springer-Verlag, Berlin

BACC author team (eds) (2009) Assessment of climate change for the Baltic Sea basin. Regional Climate Studies, SpringerVerlag, Berlin

Baltic Nest Institute (2007) Management options, nutrient loads and ecosystem responses for the Baltic Sea: policy scenarios from BNI/NEST Jan 2007. Ad hoc Task Force for the HELCOM Baltic Sea Action Plan, 4th Meeting, Helsinki, Finland, 6-7 February 2007, Helsinki Commission

Berglund J, Müren U, Bamstedt U, Andersson A (2007) Efficiency of a phytoplankton-based and a bacterial-based food web in a pelagic marine system. Limnol Oceanogr 52:121-131

Blomqvist S, Rydin E (2009) Hur fosforbindning i Östersjöns bottensediment kan förstärkas. Report, Naturvårdsverket, Stockholm

Blomqvist S, Gunnars A, Elmgren R (2004) Why the limiting nutrient differs between temperate coastal seas and freshwater lakes: a matter of salt. Limnol Oceanogr 49:22362241

Boesch D, Hecky R, O'Melia C, Schindler D, Seitzinger S (2006) Eutrophication of Swedish seas. Rep No 5509, Swedish Environmental Protection Agency, Stockholm

Boesch D, Hecky R, O'Melia C, Schindler D, Seitzinger S (2008) Eutrophication of seas along Sweden's west coast. Rep No 5898, Swedish Environmental Protection Agency, Stockholm

Canfield DE, Kristensen E, Thamdrup B (2005) Aquatic geomicrobiology. Adv Mar Biol 48

Carman R, Cederwall H (2001) Sediments and macrofauna in the Baltic Sea: characteristics, nutrient contents and distribution. In: Wulff F, Rahm L, Larsson P (eds) A systems analysis of the Baltic Sea. Springer-Verlag, Berlin

Conley DJ, Humborg C, Rahm L, Savchuk OP, Wulff F (2002) Hypoxia in the Baltic Sea and basin-scale changes in phosphorous biogeochemistry. Environ Sci Technol 36: 5315-5320

Conley DJ, Björck S, Bonsdorff E, Carstensen J and others (2009a) Hypoxia-related processes in the Baltic Sea. Crit Rev Environ Sci Technol 43:3412-3420

Conley DJ, Bonsdorff E, Carstensen J, Destouni G and others (2009b) Tackling hypoxia in the Baltic Sea: is engineering a solution? Environ Sci Technol 43:3407-3411

Diaz RJ, Rosenberg R (2008) Spreading dead zones and consequences for marine ecosystems. Science 321:926-929

> Döscher R, Meier HEM (2004) Simulated sea surface temperature and heat fluxes in different climates of the Baltic Sea. Ambio 33:242-248

Döscher R, Willén U, Jones C, Rutgersson A, Meier HEM, Hansson U, Graham LP (2002) The development of the regional coupled ocean-atmosphere model RCAO. Boreal Environ Res 7:183-192

Eilola K (2009) On the dynamics of organic nutrients, nitrogen and phosphorus, in the Baltic Sea. Oceanogr Rep No 99, SMHI, Norrköping

Eilola K, Meier HEM, Almroth E (2009) On the dynamics of oxygen, phosphorus and cyanobacteria in the Baltic Sea: a model study. J Mar Syst 75:163-184

Eilola K, Gustafson BG, Hordoir R, Höglund A and others
(2010) Quality assessment of state-of-the-art coupled physical-biogeochemical models in hindcast simulations 1970-2005. Oceanogr Rep No 101, SMHI, Norrköping

> Gordon C, Cooper C, Senior CA, Banks H and others (2000) The simulation of SST, sea ice extent and ocean heat transports in a version of the Hadley Centre coupled model without flux adjustments. Clim Dyn 16:147-166

Graham LP (2004) Climate change effects on river flow to the Baltic Sea. Ambio 33:235-241

Graham LP, Hagemann S, Jaun S, Beniston M (2007) On interpreting hydrological change from regional climate models. Clim Change 81(Suppl 1):97-122

Gustafsson BG (2004) Sensitivity of Baltic Sea salinity to large perturbations in climate. Clim Res 27:237-251

Gustafsson BG, Meier HEM, Savchuk OP, Eilola K, Axell L, Almroth E (2008) Simulation of some engineering measures aiming at reducing effects from eutrophication of the Baltic Sea. Earth Sci Rep Ser, C82, Göteborg University

Janssen F, Neumann T, Schmidt M (2004) Interannual variability in cyanobacterial blooms in the Baltic Sea controlled by wintertime hydrographic conditions. Mar Ecol Prog Ser 275:59-68

> Jönsson A, Danielsson A, Rahm L (2005) Bottom type distribution based on wave friction velocity in the Baltic Sea. Contin Shelf Res 25:419-435

Kahru M (1997) Using satellites to monitor large-scale environmentl change: a case study of cyanobacterial blooms in the Baltic Sea. In: Kahru M, Brown CW (eds) Monitoring algal blooms: new techniques for detecting large-scale environmental change. Springer-Verlag, Berlin, p 43-61

Karlson B, Eilola K, Hansson M (2010) Cyanobacterial blooms in the Baltic Sea: correlating bloom observations with environmental conditions. In: Ho KC, Zhou MJ, Qi YZ (eds) Proc 13th Int Conf on Harmful Algae, Nov. 3-7 2008, Hong Kong, p 247-252

Kauker F, Meier HEM (2003) Modeling decadal variability of the Baltic Sea. 1. Reconstructing atmospheric surface data for the period 1902-1998. J Geophys Res 108(C8):3267, doi:10.1029/2003JC001797

Langner J, Andersson C, Engardt M (2009) Atmospheric input of nitrogen to the Baltic Sea basin: present situation, variability due to meteorology and impact of climate change. Boreal Env Res 14:226-237

Marmefelt E, Arheimer B, Langner J (1999) An integrated biogeochemical model system for the Baltic Sea. Hydrobiologia 393:45-56

Meier HEM (2006) Baltic Sea climate in the late twenty-first century: a dynamical downscaling approach using 2 global models and 2 emission scenarios. Clim Dyn 27: 39-68

Meier HEM, Kauker F (2003) Modeling decadal variability of the Baltic Sea. 2. Role of freshwater inflow and large-scale atmospheric circulation for salinity. J Geophys Res C108. doi:10.1029/2003JC001799

Meier HEM, Döscher R, Faxen T (2003) A multiprocessor coupled ice-ocean model for the Baltic Sea: application to salt inflow. J Geophys Res 108(C8): 3273

Meier HEM, Döscher R, Halkka A (2004a) Simulated distributions of Baltic sea-ice in warming climate and consequences for the winter habitat of the Baltic ringed seal. Ambio 33:249-256

Meier HEM, Broman B, Kjellström E (2004b) Simulated sea level in past and future climates of the Baltic Sea. Clim Res 27:59-75

Meier HEM, Kjellström E, Graham LP (2006) Estimating uncertainties of projected Baltic Sea salinity in the late 21st century. Geophys Res Lett 33:L15705. doi:10.1029/ 
2006GL026488

Nakićenović N, Alcamo J, Davis G, de Vries B and others (2000) Emission scenarios. Special report of Working Group III of the Intergovernmental Panel on Climate Change. Cambridge University Press, Cambridge

Neumann T, Schernewski G (2008) Eutrophication in the Baltic Sea and shifts in nitrogen fixation analyzed with a 3D ecosystem model. J Mar Syst 74:592-602

Omstedt A, Gustafsson E, Wesslander K (2009) Modelling the uptake and release of carbon dioxide in the Baltic Sea surface water. Contin Shelf Res 29:870-885

Pawlak JF, Laamanen MM, Andersen JH (2009) Eutrophication in the Baltic Sea: an integrated thematic assessment of the effects of nutrient enrichment in the Baltic Sea Region, Executive Summary. Baltic Sea Environment Proc No 115A, Helsinki Commission, Helsinki

Pfeffer WT, Harper JT, O'Neet S (2008) Kinematic constraints on glacier contributions to 21st century sea-level rise. Science 321:1340-1343

Pope VD, Gallani ML, Rowntree PR, Stratton RA (2000) The impact of new physical parameterizations in the Hadley Centre climate model: HADAM3. Clim Dyn 16: 123-146

Rahmstorf S (2007) A semi-empirical approach to projecting future sea-level rise. Science 315:368-370

Räisänen J, Hansson U, Ullerstig A, Döscher R and others (2004) European climate in the late 21st century: regional simulations with 2 driving global models and 2 forcing scenarios. Clim Dyn 22:13-31

Raven J, Caldeira K, Elderfield H, Hoegh-Guldberg OP and others (2005) Ocean acidification due to increasing atmospheric carbon dioxide. Royal Society, London

Roeckner E, Bengtsson L, Feichter J, Lelieveld J, Rodhe H (1999) Transient climate change simulations with a coupled atmosphere-ocean GCM including the tropospheric sulfur cycle. J Clim 12:3004-3032

Savchuk OP, Wulff F (1996) Biogeochemical transformations of nitrogen and phosphorus in the marine environment. System Ecology Contributions, No. 2, Stockholm University

Savchuk OP, Wulff F (2007) Modeling the Baltic Sea eutrophication in a decision support system. Ambio 36:141-148

Savchuk OP, Wulff F (2009) Long-term modeling of large- scale nutrient cycles in the entire Baltic Sea. Hydrobiologia 629:209-224

Savchuk OP, Wulff F, Hille S, Humborg C, Pollehne F (2008) The Baltic Sea a century ago: a reconstruction from model simulations, verified by observations. J Mar Syst 74: 485-494

Savchuk OP, Eremina TR, Isaev AV, Neelov IA (2009) Response of eutrophication in the eastern Gulf of Finland to nutrient load reduction scenarios. Hydrobiologia 629: $225-237$

> Schernewski G, Neumann T (2005) The trophic state of the Baltic Sea a century ago: a model simulation study. J Mar Syst 53:109-124

Skoog A, Hall POJ, Hulth S, Paxeus N, Rutgers Van Der Loeff M, Westerlund S (1996) Early diagenetic production and sediment-water exchange of fluorescent dissolved organic matter in the coastal environment. Geochim Cosmochim Acta 60:3619-3629

Solomon S, Qin D, Manning M, Chen Z and others (eds) (2007) Contribution of Working Group I to the Fourth Assessment Report of the Intergovernmental Panel on Climate Change. Cambridge University Press, Cambridge

Stålnacke P, Grimvall A, Sundblad K, Tonderski A (1999) Estimation of riverine loads of nitrogen and phosphorus to the Baltic Sea 1970-1993. Environ Monit Assess 58:173-200

Stigebrandt A, Gustafsson BG (2007) Improvement of Baltic proper water quality using large-scale ecological engineering. Ambio 36:280-286

> Sundby B, Gobeil Ch, Silverberg CG, Silverberg N, Mucci A (1992) The phosphorus cycle in coastal marine sediments. Limnol Oceanogr 37:1129-1145

- Vahtera E, Conley D, Gustafsson BG, Kuosa H and others (2007) Internal ecosystem feedbacks enhance nitrogenfixing cyanobacteria blooms and complicate management in the Baltic Sea. Ambio 36:186-194

> Wulff F, Bonsdorff E, Gren IM, Johansson S, Stigebrandt A (2001) Giving advice on cost effective measures for a cleaner Baltic Sea: a challenge for science. Ambio 30: 254-259

Zillén L, Conley DJ, Andrén T, Andrén E, Björck S (2008) Past occurrences of hypoxia in the Baltic Sea and the role of climate variability, environmental change and human impact. Earth Sci Rev 91:77-92 

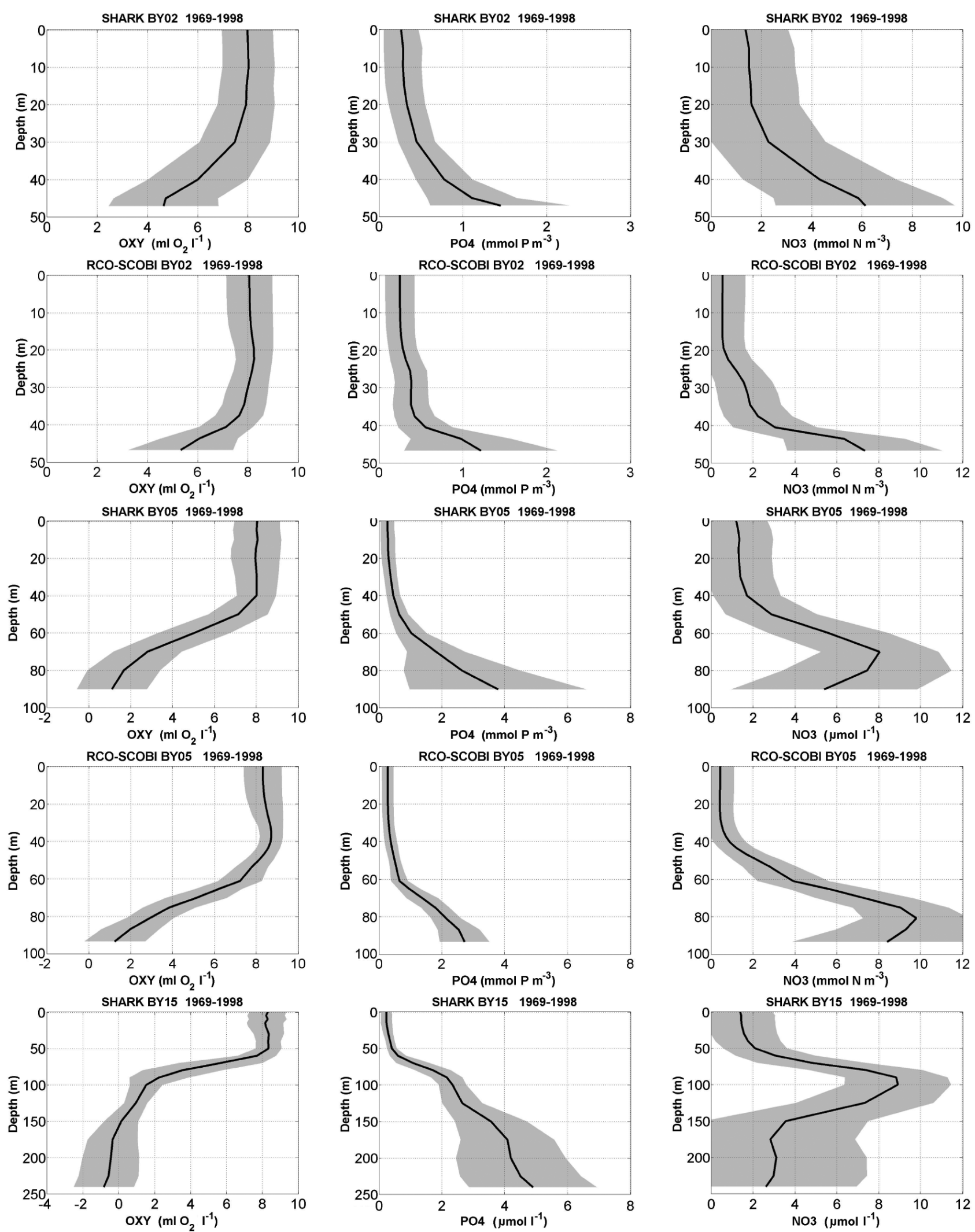

Fig. A1. Observed and RCO-SCOBI simulated (C-REF-1) mean profiles of oxygen (in $\mathrm{ml} \mathrm{l}^{-1}$ ), phosphate (in mmol $\mathrm{m}^{-3}$ ), and nitrate (in $\mathrm{mmol} \mathrm{m}^{-3}$ ) at the monitoring stations BY2, BY5, BY15, SR5 and LL07 for 1969-1998 (locations given in Fig.1). Range of variability indicated by the \pm 1 SD band calculated from model output every 2nd day, or from available observations (shaded area) 

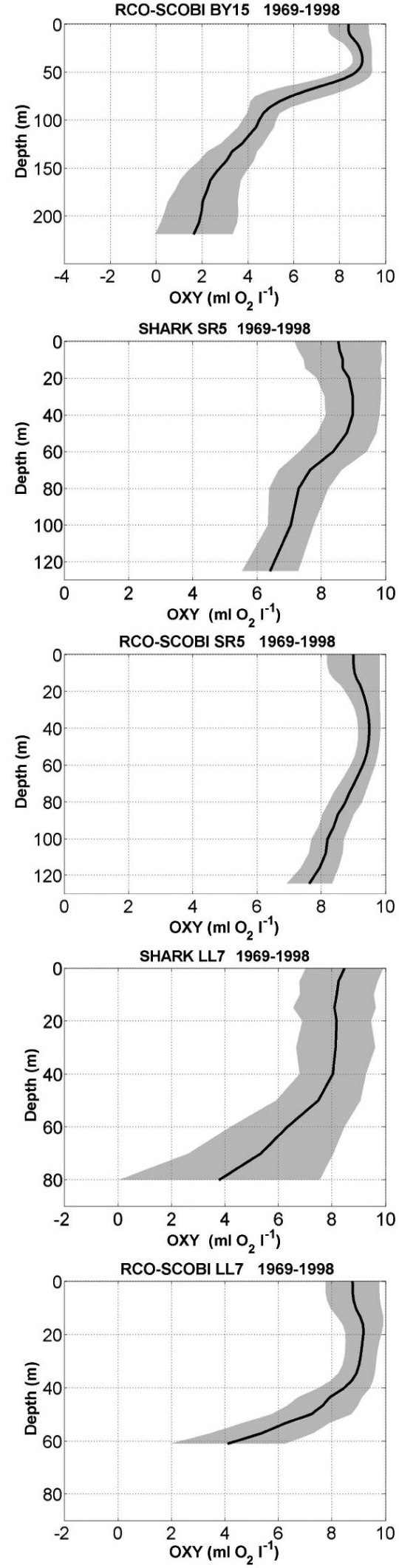
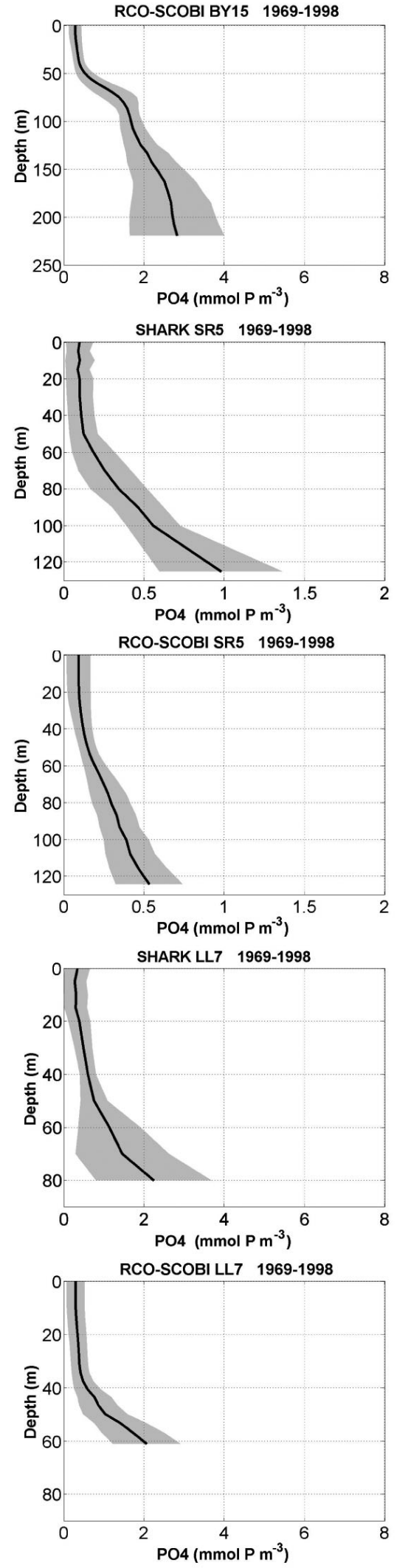

Fig. A1 (continued)
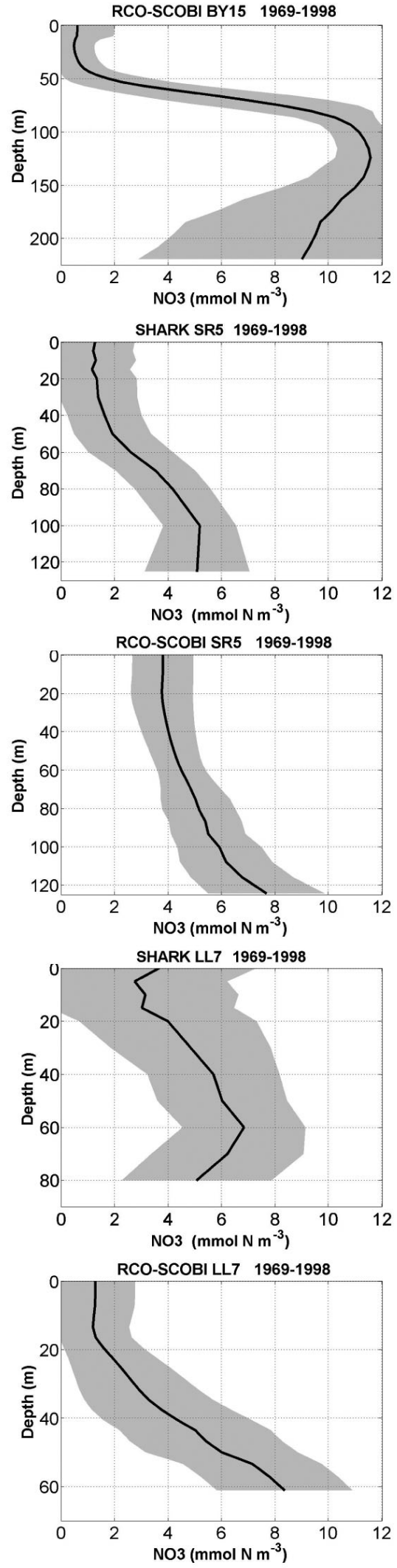